\title{
INFLUENCE OF TRANSPORT PARAMETERS AND CHEMICAL PROPERTIES OF THE SEDIMENT IN EXPERIMENTS TO MEASURE REACTIVE TRANSPORT IN SEAWATER INTRUSION
}

Nuria Boluda-Botella, Vicente Gomis-Yagües and Francisco Ruiz-Beviá.

Department of Chemical Engineering, University of Alicante. Apdo. 99. E-03080 Alicante. Spain. Nuria.boluda@ua.es.

\section{ABSTRACT}

A study of seawater intrusion under controlled laboratory conditions using multicomponent heterovalent chromatography is presented. The aim was to understand the influence of several variables on hydrogeochemical transport, especially on gypsum precipitation and cationic exchange. In addition, the study aimed to provide experimental data on how water composition changes during simulated seawater intrusion.

The experimental results show that dispersion modifies the shape of the elution curves for the different solutes for processes such as cation exchange and precipitation-dissolution. The maxima and minima of these curves are very smooth, and entirely absent in several instances. Altering the cation exchange capacity of the sediment produced changes in the height of the calcium peak and in the maxima and minima of magnesium. In several experiments the high concentrations of calcium and sulfate during the first stages of the intrusion induced gypsum precipitation. The subsequent dissolution of the gypsum raised the concentration of sulfate higher than that in seawater. Saturation indices (SI) for gypsum in the samples collected were calculated with PHREEQC (version 2). Gypsum SI values are in agreement with experimental observations.

Piper diagrams demonstrate that the experimental variables of transport parameters and cation exchange capacity (CEC) strongly influence the hydrochemistry of seawater intrusion. The experimental data deviate 
substantially from the theoretical freshwater-seawater mixing line, and the shape of the pathway between the end members depends on the experimental conditions.

The experimental data obtained during column experiments and the physical and chemical parameters determined in each experiment can be used in the validation of multicomponent transport models. These hydrogeochemical models may aid in the interpretation of field data.

Keywords: seawater intrusion; hydrochemistry; column experiment; transport parameters; cation exchange; gypsum

\section{INTRODUCTION}

Several studies have used multicomponent cation exchange approaches to describe reactive transport in porous media (Callahan et al., 2000 provides a detailed listing). Of these, Valocchi et al. (1981 a,b) developed a fundamental analysis of cation exchange process, or ion chromatography, in which treated wastewater is injected into a salinized aquifer. They subsequently proposed a model for this process. Later, Appelo and Willemsen (1987) and Appelo $(1994,1996)$ discussed the cation exchange principles involved in salinization and derived specific equations for multicomponent problems in this context.

Seawater intrusion is a particular case of multicomponent reactive transport requiring a more complex analysis because of the large number of solutes at very high concentration (ionic strength around 0.7 ) and the different types of reactions involved, such as cation exchange and precipitation-dissolution. However, a chromatographic sequence of salinization has not been clearly observed in seawater intrusion field-scale experiments, even though the $\mathrm{CaCl}_{2}$-water type is an ubiquitous indicator of salt water upconing in coastal areas (Appelo and Postma, 2005). Instead, information on the sequence of compositions for saltwater intrusions is obtained from columns or small-scale field experiments (Appelo et al., 1990, Gomis et al., 
1997, Van Breukelen et al., 1998, Andersen et al., 2005), or from multicomponent models of reactive transport (Gomis et al., 1996, Parkhurst and Appelo, 1999).

With regard to laboratory research, Beekman and Appelo (1990) performed experiments in columns $7.5 \mathrm{~cm}$ long in which they displaced fresh water with seawater that had been diluted 1:1 with distilled water. The authors modeled the chromatographic results by taking into account mainly the cationic exchange processes.

Gomis et al. (1997) carried out displacement experiments using seawater in a sediment column $100 \mathrm{~cm}$ in length. In these experiments, some of the samples taken at the exit of the column during the initial stages of the intrusion were supersaturated with gypsum, which precipitated into the sampling vials, even though the sediment did not initially contain gypsum. The chromatographic experimental results showed the signs of gypsum precipitation in the sediment column: comparison of the sulfate curve to that of chloride (a conservative solute) revealed a considerable delay.between the two solutes. The high concentrations of calcium and sulfate induce the precipitation of gypsum, and its subsequent dissolution increases the concentration of sulfate to a level higher than its concentration in seawater, as seen in the experimental results.

Moreover, applying a multicomponent reactive model to the experimental data (Gomis-Yagües et al., 2000) has shown that gypsum precipitation during the early stages of the advance of the seawater front causes a 20 decrease in sulfate concentration with respect to the conservative mixture of freshwater and seawater under conditions that are unfavorable to sulfate reduction by bacteria. Thus, gypsum precipitation may explain the non-conservative behavior of sulfate during seawater intrusion, in addition to bacterial sulfate reduction by organic matter.

25 Although an obvious decrease in sulfate concentration has been observed in previous field studies (Stuyfzand, 1992; Bocanegra et al., 1992; Custodio, 1992; Fidelibus and Tulipano, 1996), authors have either given no explanation for the decrease or have attributed it to degradation of organic matter by sulfatereducing bacteria, because field samples were not saturated with respect to gypsum. In recent years, the 
hypothesis of gypsum precipitation during seawater intrusion, first described in Gomis-Yagües et al. (2000), has increasingly been cited (Slomp and Van Cappellen, 2004). It is also discussed as a possibility in field studies on seawater intrusion phenomena (Pulido-Leboeuf, 2004). This author has argued that gypsum saturation indices are generally higher than the theoretical conservative mixing line (especially for mixtures containing less than $40 \%$ seawater). This suggests the existence of a sulfate source other than seawater. Such a source could be the dissolution of gypsum present in the metapelitic strata; in this case, gypsum need not be very abundant because saturation is not reached. The possibility of sulfate reduction or precipitation in samples containing less than $5 \%$ seawater or more than $40 \%$ seawater cannot be ignored, since these samples have saturation indices well below those calculated for conservative mixing.

Therefore, it is important to understand the chemical reactions such as gypsum precipitation and cationic exchange that affect groundwater quality during seawater intrusion. In these processes, the behavior of the chemical species depends on several factors, including differences in selectivity coefficients, the value of the cation exchange capacity of the sediment, contrasts between the chemical composition of the injected fluid and the fluid initially resident in the pores of the sediment, and dispersion (Lambrakis, 2006).

In several studies the results have proven insensitive to the dispersion characteristics of the column -- i.e., the precise value of the Péclet number -- and the shape of fronts was found to be essentially unaffected by dispersion (Vulava et al., 2002). Similarly Petales and Lambrakis (2006) found that small variations in

20 dispersion did not significantly affect the chemical composition of the groundwater across the simulated flow path, as shown in related studies (Lambrakis and Kallergis, 2000).

Therefore, the aim of this article was to investigate multicomponent heterovalent chromatography for the process of seawater intrusion as modeled under controlled laboratory conditions. We sought to understand the influence of several variables, such as dispersion and CEC, on hydrogeochemical transport, especially on gypsum precipitation and cationic exchange. We also wished to collect experimental data on how the composition of seawater changes during the intrusion process. These data and the physical and chemical 
parameters determined in each experiment can be used in the validation of multicomponent transport models.

In this study, two sets of experimental data are obtained by displacing synthetic freshwater with seawater.

5 The results are presented and compared with two other data sets from a previous paper (Gomis et al., 1997). The experiments were carried out in a sediment column $1 \mathrm{~m}$ long in an effort to increase the concentration of several ions and thereby produce conditions favorable for the precipitation of several solid phases. For example, the maximum concentration of calcium could be increased along the column and the solubility product could be attained, thereby allowing gypsum precipitation. The subsequent dissolution of this precipitated gypsum may be what produces a greater sulfate concentration than in seawater.

The experiments were carried out under different transport conditions, e.g., with variations in flow rate and dispersion. One experiment was run at the same flow rate as another presented in a previous paper, but because the sediment was different, other physical properties such as porosity were affected. Some chemical properties of the sediment have also been varied in this experiment. For example, the cation exchange capacity was varied in the sediment when a fraction of the large amount of calcite was eliminated. The resulting increase in clay content relative to the total sediment led to a higher CEC.

\section{MATERIALS AND METHODS}

\subsection{WATER AND SEDIMENT PROPERTIES}

The column experiments were performed by flushing seawater through columns packed with calciumsaturated sediment that had previously been equilibrated with freshwater. To avoid variation in initial composition between experiments, the freshwater was synthetically prepared. Its mean composition is shown in Table 1. This composition corresponds to the average composition of 43 wells in the Jávea Quaternary aquifer (Alicante, Spain) with a chloride concentration of less than $5.6 \mathrm{mmol} / \mathrm{L}(200 \mathrm{mg} / \mathrm{L}$ ) 
(Blasco, 1988). The synthetic freshwater was prepared using solutions of $\mathrm{CaCl}_{2}, \mathrm{KCl}, \mathrm{Na}_{2} \mathrm{SO}_{4}, \mathrm{MgSO}_{4}$, and solid $\mathrm{CaCO}_{3}$. The mixed solution was bubbled with $\mathrm{CO}_{2}$ to achieve complete dissolution of solid $\mathrm{CaCO}_{3}$ and adjusted to $\mathrm{pH} 7$ by means of heating and stirring. Displacement experiments were carried out using seawater which was sampled several times on the Alicante coast. Average concentrations are reported in Table 1.

Two different sediments were used in the column experiments. The first is natural sediment taken from the Jávea Quaternary aquifer system located on the southeastern coast of Spain, between Valencia and Alicante. The UTM coordinates of the sampling were $255.200,4296.750,10$, a depth of $3 \mathrm{~m}$, and a distance from the sea of $300 \mathrm{~m}$. The mineralogical composition of the sediment by weight was $53 \%$ calcite, $35 \%$ quartz, and $12 \%$ clay; the elemental chemical composition, particle size distribution, clay composition, and other sediment properties are reported elsewhere (Gomis et al., 1997). The other sediment was obtained by modifying the first through treatment with hydrochloric acid to reduce the carbonate content, which increased its CEC. This sediment is referred to in this paper as "treated sediment," while the first is referred to as "natural sediment." The initial $\mathrm{CaCO}_{3}$ in the natural and treated sediment was estimated by calcination at $800{ }^{\circ} \mathrm{C}$ and found to make up $53 \%$ and $36 \%$ of the total weight, respectively.

The CEC of the natural sediment was determined by the sodium acetate saturation method $(7 \mathrm{meq} / 100 \mathrm{~g})$ and exchange complex composition in batch equilibration using ammonium acetate (Gomis et al., 1997).

20 Sullivan et al. (2003) and Carlyle et al. (2004) used solutions of $\mathrm{LiBr}$ and $\mathrm{LiCl}$, respectively, to determine CEC and sorbed ions. In this study, however, we used the method described by Andersen et al. (2005), in which $1 \mathrm{M} \mathrm{NaCl}$ and $1 \mathrm{M} \mathrm{NH}_{4} \mathrm{Cl}$ solutions are used on separate sub-samples. The displacement of the sorbed ions by $\mathrm{NaCl}$ occurs by a process similar to that observed in seawater intrusion. Pore solutions and exchange complex composition for the natural and treated sediment, as determined by $\mathrm{NaCl}$ and $\mathrm{NH}_{4} \mathrm{Cl}$ saturation methods, are shown in Table 2 . The CEC in treated sediment was $10 \mathrm{meq} / 100 \mathrm{~g}$, identical to that reported in the field experiment of Valocchi et al. (1981). 


\subsection{EXPERIMENTAL SET-UP}

The experimental equipment (Figure 1) consisted of a stainless steel column thermostatted at $25{ }^{\circ} \mathrm{C}$ and connected to an HPLC Shimadzu LC-5A or LC-9A pump, with ascending flux. These pumps permitted a small constant flow of water to be introduced to try to achieve local chemical equilibrium with the sediment and, at the same time, to simulate the slow speed of seawater intrusion processes. The length of the stainless steel column was $1 \mathrm{~m}$, and the internal diameter was $3.16 \mathrm{~cm}$ (for other details, see Boluda Botella, 1994, and Gomis et al., 1997). This slow speed and the large size of the columns meant that some of the experiments lasted nearly four months. The goal with such large columns is to amplify changes in concentration and simulate more realistically the long path found along a flowline in an aquifer. This long path can increase the concentration peaks of some solutes and exert specific effects on other solutes, for example, to increase calcium concentration and cause gypsum to precipitate, as observed in Gomis-Yagües et al. (2000).

\subsection{DESCRIPTION OF THE EXPERIMENTS}

The sediments in the column were prepared before starting the column displacement experiments. Initially the sediments were dried, passed through a 2-mm sieve and saturated in batch with synthetic freshwater. Afterwards the sediments were introduced into the column in small quantities, in order to achieve a homogeneous distribution of particles inside the column. When the column was full, the HPLC pump was connected to it and freshwater was flushed through at a constant flow rate. The injection of fluid produced a compaction of the sediments and thus had to be repeated several times to complete the filling of the column. In this procedure, the porosity obtained in each experiment corresponded to the flow rate of the specific experiment, and the porosity also depended on the characteristics of the sediment and the ratio of freshwater 
to sediment. The filling operation was considered finished once the columns were completely filled with sediment and the pore water had the composition of freshwater. This filling operation lasted several months.

Laboratory intrusion experiments started when the prepared columns, filled either with 'natural sediment' (Experiment A) or with 'treated sediment' (Experiment B), were flushed continuously with a constant flow of seawater, at the same flow rate used in the synthetic fresh water saturation procedure. From $t=0$, seawater was pumped continuously from the bottom to the top of the column. The flow was controlled continuously during the experiments based on the weight of water fractions collected in a given period. Experiment A was carried out at a mean flow rate of $82 \mathrm{mg} / \mathrm{min}$; Experiment $\mathrm{B}$, at $20 \mathrm{mg} / \mathrm{min}$. Fluctuations with respect to the mean flow were small.

In each of the experiments the effluent was collected in small fractions (approximately $20 \mathrm{~g}$ ), and the concentrations of $\mathrm{Cl}, \mathrm{S}$, total inorganic carbon (TIC), $\mathrm{Na}, \mathrm{K}, \mathrm{Ca}, \mathrm{Mg}$, and $\mathrm{pH}$ were determined in the laboratory. The accuracy of solute analysis was estimated from the electrical balance. For most samples it was generally of the same order as, or less than, $2 \%$; for a few samples, it was less than $4 \%$. The methods described in APHA-AWWA-WPCF (1998) were used. The collected samples of water were analyzed to determine the variation in solute concentration time (Boluda-Botella et al., 2004). TIC and pH were determined immediately after the sample was collected at the outlet of the column. TIC was determined outside of the column by titration with $0.01 \mathrm{~N} \mathrm{HCl}$; a pH meter was used to determine the equivalence points of carbonate and bicarbonate. The experiments were judged complete when the solute concentrations in the effluent were equal to the solute concentrations of the seawater.

In Experiment B several sampling vials were found to contain a precipitate after a period of time. The precipitate was analyzed and found to correspond to calcium sulfate. The determination of sulfate and calcium in the sampling vials was carried out separately in the dissolved phase and in the precipitated phase. 


\section{RESULTS AND DISCUSSION}

\subsection{DETERMINATION OF COLUMN TRANSPORT PARAMETERS}

Laboratory column experiments should be carried out under specific transport conditions that are determined in advance for each system. In the case of seawater intrusions, the chloride can be considered to be the tracer for the system, and its breakthrough curve contains all the necessary information on hydrodynamic and physical characteristics of the column.

Computer programmes such as PHREEQC (Parkhurst and Appelo, 1999) or IMPACT (Jauzein et al., 1989) are useful for modelling reactive transport in porous media, but the best fit of the chloride breakthrough curve must be calculated through trial and error. CXTFIT by Toride et al. (1995), available from the US Soil Salinity Lab (Riverside, CA), can perform the least squares fitting in MS-DOS.

A graphical user interface was designed with Microsoft Visual Basic 6.0 to carry out this fitting procedure. ACUAINTRUSION (Boluda Botella et al., 2006) calculates the best fit of the experimental data [chloride concentration $(\mathrm{mmol} / \mathrm{L})$ versus experimental time $(\mathrm{h})]$. The analytical solution of the convection-dispersion equation (Lapidus and Amundson, 1952) is

$$
C(L, t)=C_{i}+\frac{\left(C_{0}-C_{i}\right)}{2}\left[\operatorname{erfc}\left(\frac{L-v t}{\sqrt{4 D_{L} t}}\right)+\exp \left(\frac{v L}{D_{L}}\right) \operatorname{erfc}\left(\frac{L+v t}{\sqrt{4 D_{L} t}}\right)\right]
$$

where $\mathrm{C}(\mathrm{L}, \mathrm{t})$, is the chloride concentration at the output stream of the column; $\mathrm{C}_{\mathrm{i}}$, the initial concentration of the chloride in the freshwater; $\mathrm{C}_{0}$, the concentration of chloride in the seawater; $\mathrm{L}$, column length; $\mathrm{t}$, time; $\mathrm{v}$, interstitial water velocity in the direction of propagation (equal to Darcy velocity divided by porosity, or $\mathrm{u} / \varepsilon)$; and $\mathrm{D}_{\mathrm{L}}$, the longitudinal dispersion coefficient. 
To obtain the best fit, the square of the mean deviation between experimental and calculated compositions is minimized. The program then provides the following calculated transport parameters (Table 3): mean residence time $\mathrm{T}_{\mathrm{m}}(\mathrm{L} / \mathrm{v})$, Péclet number $\left(\mathrm{Pe}=\mathrm{vL} / \mathrm{D}_{\mathrm{L}}\right)$, effective porosity $\varepsilon$, interstitial velocity $\mathrm{v}(\mathrm{u} / \varepsilon)$, dispersion $\mathrm{D}_{\mathrm{L}}$, and dispersivity $\alpha(\mathrm{L} / \mathrm{Pe})$. The dispersion coefficient can be expressed as the contribution of two parameters: $D_{L}=D_{d}+\alpha v$, where $D_{d}$ is the diffusion coefficient, which can be ignored because the flow velocity in the column is sufficiently high to cause a dispersion-dominated spreading (Appelo and Postma, 2005). The Péclet number can be interpreted as the effect of the ratio of advection to dispersion on solute transport.

10

Using these definitions, transport parameters were determined for the experiments presented in this paper (Experiments A and B). The same model was applied to column experiments in a previous study carried out with natural sediment but at different flow rates (Gomis et al., 1997). Experiment I (Exp. I) was run at 20 $\mathrm{mg} / \mathrm{min}$, and Experiment II (Exp. II) at $35 \mathrm{mg} / \mathrm{min}$. Table 3 includes the transport parameters obtained for the previous (I and II) and present (A and B) experiments.

The parameters obtained for Experiments A and B differ slightly from those published in the previous paper, which reflects the need to achieve the best fit by trial and error. For example, the Péclet number obtained in Experiments I and II was 150 instead of the respective values of 188 and 166 obtained in the present study.

Experiment A used a greater velocity $(0.63 \mathrm{~cm} / \mathrm{h})$ than the other experiments, but this value still lies within the velocity range used in field experiments. For instance, Petalas and Lambrakis (2006) estimated that the rate of seawater intrusion in the study area was approximately $0.6 \mathrm{~km} / \mathrm{yr}(0.685 \mathrm{~cm} / \mathrm{h})$. The calculated porosity value is similar to those for Experiments I and II, carried out with the same sediment. The combined effect of the greater porosity $(0.41)$ and a greater flow rate of water through the column (82 
$\mathrm{mg} / \mathrm{min})$ led to a significantly higher dispersion coefficient $\left(27.3 \mathrm{~cm}^{2} / \mathrm{h}\right)$ and dispersivity $(17.7 \mathrm{~cm})$ and a small Péclet number (5.6).

Experiment B was carried out at the same flow rate as Experiment I (20 mg/min), but the modified sediment, which had a higher clay content and therefore higher CEC, caused a lower porosity $(0.31)$ than in Experiment I (0.37). Consequently, the mean residence time was lower (203 h) than in the previous experiment $(241 \mathrm{~h})$. The Péclet number, 147, was of the same order of magnitude as in Experiments I and II, as were the dispersion coefficient and the dispersivity -- at the same time, these values were very different from those obtained in Experiment A. -- The small porosity value in Experiment B is in the range of the field-experiment data: Bjerg et al. (1993) determined an effective porosity of 0.33 in a sandy aquifer, Martinez and Bocanegra (2002) measured a porosity of 0.3 as well as an intrusion rate of $0.5 \mathrm{~m} /$ day (2 $\mathrm{cm} / \mathrm{h}$ ), which is greater than in all of the column experiments performed in this work.

The porosity of the sediments (natural and treated) were determined in Experiments A and B once the seawater intrusion trials had run their course. In both cases, the experimental porosity was determined by evaporating the water of a known volume of sediment at $105^{\circ} \mathrm{C}$. The porosity determined in more than 10 portions of the column was practically identical to the value calculated by ACUAINTRUSION from the chloride breakthrough curve.

20 Experimental results for the conservative $\mathrm{Cl}(\mathrm{mmol} / \mathrm{L})$ versus time $(\mathrm{h})$ are represented using symbols in Figure 2 (a). In the same figure, lines represent the best fit of the experimental data using the ACUAINTRUSION interface. The same $\mathrm{Cl}$ breakthrough curves are presented in dimensionless time (time/ $\mathrm{t}_{\mathrm{m}}$ ) in Figure 2 (b). It is worth noting the coincidence of breakthrough curves for three of the experiments, with the exception of Experiment $\mathrm{A}$, which was carried out at $\mathrm{Q}=82 \mathrm{mg} / \mathrm{min}$ and which had a smaller slope at the breakpoint. This is because the dispersion was greater than in the other experiments. 
The objective of testing different conditions in the column experiments was to study the influence of several variables on the chromatographic curves and to derive a set of physical and chemical parameters that would facilitate the validation of hydrogeochemical models.

5 The first experiment (Experiment A) was carried out with natural sediment at a flow rate of $82 \mathrm{mg} / \mathrm{min}$. In order to obtain transport parameter values different from those of previous experiments, the filling procedure of the column was varied: the ratio of freshwater to sediment in the initial mixture packed into the column was higher. As a result, the sediment underwent less compaction and the porosity was therefore greater. In this experiment, the samples did not precipitate into the sampling vials after each fraction was collected. This suggests that they were all undersaturated with respect to gypsum. This is the main chemical difference between the results observed here and those obtained in previous experiments (Gomis et al., 1997).

The other experiment (Experiment B) was carried out using sediment that had been treated with acid in 15 order to increase the CEC. The flow rate was approximately the same as in Experiment I (20 mg/min). However, the values of the transport parameters were different in the two experiments, which may have caused changes in the chemical reactions. In the present experiment, a solid phase precipitated in the sampling vials after the sample was collected, and the subsequent dissolution and analysis confirmed that the precipitate corresponded to gypsum. This has also been reported in previous studies (Gomis et al., 20 1997).

\subsubsection{SHAPE AND LOCATION OF CONCENTRATION CURVES}

25 Experimental data obtained in Experiments A and B are presented in Figures 3a and 3b. These data include the concentration of the $\mathrm{Cl}, \mathrm{S}, \mathrm{TIC}, \mathrm{Na}, \mathrm{K}, \mathrm{Ca}$, and $\mathrm{Mg}$ in the effluent relative to their concentration in seawater plotted against dimensionless time (i.e., pore volumes). 
For comparison with the present results, the findings from two previously published experiments (Gomis et al., 1997) are shown in Figure 3c. The earlier experiments were performed using the same sediment but different flow rates (20 and $35 \mathrm{mg} / \mathrm{min}$ ), and they yielded a similar Péclet number. The representation of the solute concentration on the dimensionless time axis $\left(\mathrm{time} / \mathrm{t}_{\mathrm{m}}\right)$ shows the curves for each solute in both 5 Experiments I and II overlap exactly.

In Figure 3a (Experiment A) the elution curves of the different solutes are similar to the chloride breakthrough curves, except for calcium. This cation's concentration should vary between that of freshwater $(3.13 \mathrm{mmol} / \mathrm{L})$ and seawater $(11.3 \mathrm{mmol} / \mathrm{L})$, but it exhibits a peak concentration as a result of the liberation of calcium from ion exchange sites in the sediment due to exchange with other cations. The concentration curves for the other cations are delayed relative to that of $\mathrm{Cl}$ in the following order: magnesium $<$ sodium $<$ potassium, with potassium showing the greatest delay. The sulfate and chloride breakthrough curves are synchronous, indicating that gypsum precipitation did not occur in this experiment. TIC shows small concentration changes as a result of the similarity between freshwater and seawater concentrations, as well as the small contribution from possible precipitation-dissolution of calcite.

The curve shapes in Figure 3b (Experiment B) are similar to those in Figure 3c, which were published previously (Experiments I and II). The concentration waves of sodium and potassium are delayed with respect to that of chloride because sodium and potassium replace the calcium in the clay during the first steps of the saltwater intrusion. As the selectivity coefficient for potassium vs. sodium is very large, the concentration wave of potassium shows a significant delay, as noted by previous investigators (Appelo and Geinaert; 1983, Ruiz et al., 1990). This phenomenon indicates that the theoretical increase in K accompanying the intrusion of seawater is reduced by the strong adsorption of this solute: $\mathrm{K}$ is accommodated easily in the interlayer space of clay minerals. Consequently, adsorption of potassium is five times greater than that of Na. In contrast, a high peak concentration appears for calcium when this cation is displaced at ion-exchange sites. The maximum concentration of calcium is found to be more than 20 times its concentration in seawater, as observed in the previous experiments, despite the higher CEC in the present experiment. With respect to magnesium in solution, the substitution and ability of all cations to 
occupy the ion exchange sites (Gomis et al., 1996) causes a small concentration peak soon after the start of the experiment, although the peak is smaller than in Experiments I and II. As the experiment proceeds, the concentration wave becomes similar to the breakthrough curves for other solutes, although the wave for magnesium appears to be even more delayed than for sodium.

Similar results were obtained with sulfate concentrations (Figs. $3 b$ and $3 c$ ): these curves show a delay with respect to the chloride curve. This fact indicates sulfate precipitation in the first stages of the intrusion, as a result of the high concentrations of calcium liberated and of the sulfate in the seawater, which produces precipitation of gypsum. Its subsequent dissolution causes the concentration of sulfate to exceed that found in seawater, as seen in the maximum concentrations observed in Experiments I and II.

\subsubsection{COMPARING CONCENTRATION CURVES FOR EACH SOLUTE}

As discussed in the previous section, comparison of the experimental chloride breakthrough curves (Figs. 2a and $2 \mathrm{~b}$ ) shows greater dispersion in Experiment $\mathrm{A}$ than in the other experiments. This fact has repercussions for chemical changes, which will be analyzed in this section. In Figure 4, two types of representation are seen: concentration $(\mathrm{mmol} / \mathrm{L})$ versus time $(\mathrm{h})$, or concentration $(\mathrm{mmol} / \mathrm{L})$ versus dimensionless time (i.e., pore volume). The latter is necessary for understanding concentration changes independently of column characteristics. Their calculation requires information about the transport characteristics, such as the mean residence time $\mathrm{t}_{\mathrm{m}}$ (dimensionless time $=\mathrm{t} / \mathrm{t}_{\mathrm{m}}$ ).

Calcium concentration (Figs. 4a and 4b) reached a maximum of $210 \mathrm{mmol} / \mathrm{L}$ in the previously published experiments (Experiments I and II), but the concentration was lower in Experiment A (100 mmol/L). This indicates that dispersion has a considerable effect on the concentration curves of calcium, since three experiments have now been carried out under similar conditions -- i.e., the same chemical characteristics for the sediment -- but with different porosities and dispersion. Experiment B, on the other hand, which was carried out at a flow rate similar to that of Experiment $\mathrm{I}(\mathrm{Q}=20)$, gave a high calcium concentration (260 $\mathrm{mmol} / \mathrm{L}$ ) due to the high CEC of the sediment. 
The influence of dispersion and CEC can also be observed in other experimental curves. In the case of magnesium in Experiment A (Figs. 4c and 4d), the greater dispersion coefficient produces a magnesium breakthrough curve similar to that of chloride. Experiments I and II, however, show a marked adsorption of magnesium, which produces an initial maximum in concentration followed by a relative minimum. The causes of the marked adsorption of magnesium have been described previously (Gomis et al., 1996); they relate to the competition among cations for the limited number of exchange sites. The magnesium curve in Experiment B shows a shape similar to those in the previous experiments, but the relative maximum and minimum are less pronounced. Thus, treatment of the sediment to remove some calcite increases the CEC, but surprisingly it decreases the relative maximum for magnesium.

Breakthrough curves similar in shape to that for chloride are observed for sodium and potassium (Figs. 4e4h). A markedly greater dispersion of sodium is observed in Experiment A with respect to the other curves, as can be seen in the graph plotted using dimensionless time. In the case of potassium, Experiment B versus

15 time $\mathrm{t}(\mathrm{h})$ is in agreement with the results in Experiment $\mathrm{I}$, which was carried out at the same flow rate but with a lower CEC. However, it is important to bear in mind that these two experiments differ in CEC, porosity, and other parameters, so it is necessary to consider dimensionless time charts in order to compare their real behaviour. Although the real-time profiles overlap almost perfectly between the two experiments, their differences become more prominent when considering dimensionless times curves. Similarly, the 20 dimensionless time scale is necessary to test whether the coincidence between experiments I and II is genuine (Gomis et al., 1997) and to reveal that Experiment B shows a delay with respect to previous experiments.

The observations made about other solutes apply also to sulfate. In Figure 5b, exact agreement is observed between Experiment B and Experiments I and II, with a small relative maximum in the sulfate curve, according to Gomis et al. (1997). However, in contrast to the previous experiments, Experiment A does not show the maximum. Perhaps in this case, the calcium concentration is not high enough to exceed the solubility product of gypsum. Therefore, there is neither precipitation nor subsequent redissolution of 
calcium sulfate, which would have caused the sulfate concentration to exceed that in seawater. This reasoning applies to all the instances in this study in which no precipitation was observed.

TIC was determined outside of the column, but in several cases it was not analyzed because of insufficient sample. This study pays less attention to this solute, since concentration changes do not differ significantly between freshwater $(3.28 \mathrm{mmol} / \mathrm{L})$ and seawater $(2.13 \mathrm{mmol} / \mathrm{L})$. In spite of the small variation between TIC concentrations in freshwater and seawater, the difference between the maximum and minimum concentrations detected in several experiments is in the range of several $\mathrm{mmol} / \mathrm{L}(3-4 \mathrm{mmol} / \mathrm{L})$. The decreases and increases in bicarbonate are probably due to precipitation-dissolution of calcite, as reported elsewhere (Rezaei et al., 2005).

In conclusion, the different characteristics of transport parameters, for instance dispersion or Péclet number, can modify the shape of fronts in seawater intrusion processes and therefore affect the chemical composition of the groundwater across the flow path, contrary to what Vulava (2002) and Petales and

15 Lambrakis (2006) assert. This conclusion is reflected in the different breakthrough curves obtained when dispersion varies (as a result of variation in porosity and flow rate) with all other conditions held constant (same sediment, freshwater, seawater, and column dimensions). The shape of wave fronts are modified when the Péclet number is small (high dispersitivity), and the maxima and minima produced by the different reactions--such as cation exchange and precipitation-dissolution--are very smooth, and even absent

20 in several instances. In addition, chemical characteristics affect the shape of the concentration curves, and it is therefore necessary to know the specific characteristics of the sediment, such as CEC or selectivity coefficients. In field studies, researchers typically use values obtained from the database of hydrogeochemical models to simulate concentration changes, and they are generally unaware of the importance of knowing the chemical characteristics of the sediment.

Therefore, knowledge of both the physical and chemical characteristics is necessary for understanding and simulating reactive transport processes during seawater intrusion. It is obvious that the uncertainties in field 
data require certain assumptions, but these assumptions can nevertheless lead to considerable errors when predicting and simulating chemical changes.

\subsubsection{PIPER DIAGRAMS}

The Piper diagrams for Experiments A and B are shown in Figure 6. The continuous directed lines represent the pathway between freshwater and seawater, and the dashed line represents the theoretical freshwaterseawater mixing line. The end members are the same for the two experiments -- freshwater and seawater -but the conditions (e.g., flow rate, CEC) slightly modify the pathway between the two waters. Experiments I and II are not shown because their Piper diagrams are similar to those of the other experiments and also because their pathways fall between those of Experiments A and B.

15

In all cases, the experimental anion concentrations are in good agreement with the theoretical anion freshwater-seawater mixing line, in contrast to the cation concentrations, which appear below the theoretical line. Changes in reactive transport produce the variation in cation concentration with respect to the mixing between freshwater and seawater concentrations. A minor difference between the theoretical mixing lines of

20 Experiment $\mathrm{A}$ and those of the other experiments is observed, analogous to the concentration changes in Figure 3a compared to those in Figures $3 b$ and $3 c$. The longer path corresponds to Experiment B, where the solute concentration changes are bigger than in the other experiments.

Field concentration changes with respect to the theoretical mixing line are readily depicted using Piper

25 diagrams. For example, Pulido-Leboef (2004) carried out a field-induced seawater intrusion experiment, and the results were compared with the straight line between the end members. Experimental cation results were below the theoretical freshwater-seawater mixing line in the cation ternary, which indicates that seawater intrusion produced reaction changes analogous to those in the column experiments presented here. 


\subsubsection{SATURATION INDICES}

5 PHREEQC (version 2) was used to calculate the saturation indices (SI) of gypsum, calcite, and dolomite in samples obtained during column experiments (Figure 7). The default database used was phreeqc.dat.

Experiment A, with its greater dispersion, has negative gypsum SI values, in agreement with experimental observations: the collected samples do not precipitate into the sampling vials, the sulfate curve is not delayed relative to the chloride one, and the concentration of calcium is low compared to the other experiments. The other experiments involve different conditions, but they yield similar results: several samples have positive gypsum SI values, corresponding to greater amounts of calcium and sulfate.

The calculated calcite and dolomite SI is positive for all samples except for the first few of Experiment I. The oversaturated samples indicate that calcite and dolomite dissolution is not possible and, as a consequence, the calcium obtained in the effluent may come from clay, which was saturated with freshwater high in calcium at the start of the experiment.

Lambrakis (2006) investigated the effects of water-rock and carbonate rock interactions by calculating saturation indices for calcite, dolomite, and gypsum. Most of the samples are saturated with dolomite and calcite, while all samples are undersaturated with gypsum. According to Plummer et al. (1990), in an aquifer containing calcite, one might expect that groundwater is close to the equilibrium with respect to this mineral. If gypsum is also present, the increased calcium concentration -- due to gypsum's dissolution or transfer from clay as in seawater intrusions -- may cause calcite to precipitate. The carbonate concentration

25 decreases as calcite precipitates, and this may induce the dissolution of dolomite (dedolomitization), if it is present. In the present experiments, small changes in TIC are observed at the same time that calcium or magnesium concentrations vary. Calcite, magnesite and other minerals may precipitate when TIC decreases, which therefore increases later when the mineral redissolves. 


\section{CONCLUSIONS}

5 Four experiments, carried out under different conditions, have been compared. Two had already been published (Gomis et al., 1997) and involved the same physical and chemical characteristics but different flow rates. The results of the two published experiments show perfect agreement, when concentration curves are plotted using dimensionless time.

10 Another experiment was carried out with the same chemical characteristics (same fresh water, seawater, sediment characteristics, and column length and diameter), but the flow rate and porosity were modified in order to assess the effects of column transport parameters, such as Péclet number (Pe), on the experimental results. The Pe number modifies the shape of the elution curves for the different solutes. If Pe is small (high dispersivity), the curves have a shape similar to that of the chloride breakthrough curve, where the several

15 maxima and minima resulting from different reactions (cation exchange and precipitation-dissolution) are very smooth. Saturation indices for gypsum in the samples collected were calculated with PHREEQC (version 2). Negative gypsum SI values are in agreement with experimental observations: the samples collected do not precipitate into the sampling vials, the sulfate curve is not delayed relative to the chloride curve, and the concentration of calcium is lower than in other experiments.

The effect of increasing cation exchange capacity was studied in the last experiment. In this case, the sediment was treated with hydrochloric acid to decrease the calcium carbonate content and induce a high clay content. The physical characteristics (e.g., column dimension and flow rate) were similar to that for one of the previous experiment, but the porosity changed as a result of the high clay content. The altered cation exchange capacity of the sediment produced changes in the height of the calcium peak and in the maxima and minima of magnesium. The sulfate curves for this experiment and for the published previously show a delay with respect to the chloride curve. The high concentrations of calcium and sulfate during the first stages of the intrusion may produce gypsum. Its subsequent dissolution may cause the concentration of 
sulfate to exceed that of seawater (Gomis et al., 2000). PHREEQC (version 2) provides positive gypsum SI values for several samples from experiments with less dispersion.

Piper diagrams demonstrate that experimental conditions (transport parameters and CEC) strongly influence the hydrochemistry of seawater intrusion. The experimental data deviate substantially from the theoretical freshwater-seawater mixing line, and the shape of the pathway between the end members depends on the experimental conditions.

\section{ACKNOWLEDGEMENTS}

This study was partially supported by the "Conselleria de Cultura, Educació i Ciencia de la Generalitat Valenciana" and "Diputación Provincial de Alicante." The authors are grateful to Beatriz Alvarez for carrying out one of the column experiments. Dr. Charlet and two anonymous reviewers contributed to the improvement of the manuscript.

\section{REFERENCES}

APHA-AWWA-WPCF (American Public Health Association), 1998. Standard Methods for the

20 Examination of Water and Wastewater. Am. Public Assoc., Washington, DC, 20th edition.

Andersen, M.S., Jakobse, V.N.R. and Postma, D., 2005. Geochemical processes and solute transport at the seawater/freshwater interface of a sandy aquifer. Geochimica et Cosmochimica Acta 69 (16): 3979-3994. Appelo, C.A.J., 1994. Some calculations on multicomponent transport with cation-exchange in aquifers. Ground Water 32 (6): 968-975.

25 Appelo, C.A.J., 1996. Multicomponent ion exchange and chromatography in natural systems. In: Lichtner, P.C., Steefel, C.I., Oelkers, E.H. (eds.). Reactive Transport in Porous Media. Rev Mineral.., vol. 34. Mineralogical Society of America, Washington, DC, pp. 193-227. 
Appelo, C.A.J. and Geinaert, W., 1983. Processes accompanying the intrusion of salt water. Geol. Appl. Idro, XVIII: 29-40.

Appelo, C.A.J. and Postma, D., 2005. Geochemistry, groundwater and pollution. $2^{\text {nd }}$ Ed. Balkema, Rotterdam, Netherlands. 535 pp.

Appelo, C.A.J. and Willemsen, A., 1987. Geochemical calculations and observations on salt water intrusions, I. A combined geochemical /mixing cell model. Journal of Hydrology, 94: 313-330.

Appelo, C.A.J., Willemsen, A., Beekman, H.E. and Griffioen, J., 1990. Geochemical calculations and observations on salt water intrusions. II. Validation of a geochemical model with laboratory experiments. Journal of Hydrology, 120: 225-250.

Beekman, H.E. and Appelo, C.A.J., 1990. Ion chromatography of fresh- and salt-water displacement: laboratory experiments and multicomponent transport modelling.

Bjerg, P. L., Ammentorp, H. C. and Christensen, T.H., 1993. Model simulations of a field experiment on a cation exchange-affected multicomponent solute transport in a sandy aquifer. J. Cont. Hydrol., 12: 291-311. Blasco, P., 1988. Estudio hidroquímico del acuífero del cuaternario de Jávea. Ph.D. Thesis, Universidad de Alicante.

Bocanegra, E.M., Martínez, D.E., Massone, H.E. and Cionchi, J.L., 1992. Exploitation effect and salt water intrusion in the Mar del Plata aquifer, Argentina. Proceedings of the 12th Salt-Water Intrusion Meeting, Barcelona, CIHS-CIMNE, 177-191.

Boluda Botella, N., 1994. Estudio hidrogeoquímico de la intrusión marina. Simulación experimental y 20 desarrollo de un modelo teórico. Tesis Doctoral. Universidad de Alicante. España.

Boluda-Botella, N., Gomis-Yagües, V., Ruiz-Beviá, F. and Saquete-Ferrándiz, MD., 2004. Gypsum precipitation/dissolution during seawater intrusion. 18th Salt Water Intrusion Meeting. Cartagena (Spain). Boluda Botella, N., Gomis, V. and Pedraza, R., 2006. ACUAINTRUSION - A graphical user interface for a hydrogeochemical seawater intrusion model. In: 1st SWIM-SWICA. Cagliary (Italy).

25 Callahan, T.J., Reimus, P.W., Bowman, R.S., Haga, M.J., 2000. Using multiple experimental methods to determine fracture/matrix interaction and dispersion of nonreactive solutes in saturated volcanic rock. Water Resour. Res. 36 (12), 3547-3558. 
Carlyle, H.F., Tellam, J.H. and Parker, K.E., 2004. The use of laboratory-determined ion exchange parameters in the predictive modelling of field-scale major cation migration in groundwater over a 40 -year period. J. Cont. Hydrol., 68: 55-81.

Custodio, E., 1992. Preliminary outlook of salt water intrusion conditions in the Doñana National Park

5 (Southern Spain). Proceedings of the 12th Salt-Water Intrusion Meeting, Barcelona, CIHS-CIMNE, 295315.

Fidelibus, M.D. and Tulipano, L., 1996. Regional flow of intruding sea water in the carbonate aquifers of Apulia (Southern Italy). Proceedings of the 14th Salt-Water Intrusion Meeting, Malmö, Sweden, 230-240.

Gomis, V., Boluda, N. and Ruiz, F., 1996. Application of a model for simulating transport of reactive multispecies components to the study of the hydrogeochemistry of salt water intrusions. J. Cont. Hydrol., 22: $67-81$.

Gomis, V., Boluda, N. and Ruiz, F., 1997. Column displacement experiment to validate hydrogeochemical models of seawater intrusions. J. Cont. Hydrol., 29, 81-91.

Gomis-Yagües, V., Boluda-Botella, N. and Ruiz-Beviá, F., 2000. Gypsum precipitation as an explanation of the decrease of sulfate concentration during seawater intrusion. J. of Hydrol., 228, 48-55.

Jauzein, M., André, C., Margrita, R., Sardin, M. and Schweich, D., 1989. A flexible computer code for modelling transport in porous media: IMPACT. Geoderma, 44: 93-113.

Lambrakis, N., 2006. Multicomponent heterovalent chromatography in aquifers. Modelling salinization and freshening phenomena in field conditions. J. of Hydrol 323: 230-243.

20 Lambrakis, N. and Kallergis, G., 2000. Freshening under natural conditions of coastal aquiferspolluted from sea water intrusion. In: Proceedings of the Third International Conference on the Geology of the Eastern Mediterranean, Nicosia, Cyprus, pp. 341-345.

Lapidus, L. and Amundson, N.r., 1952. Mathematics of adsorption in beds. VI. The effect of longitudinal diffusion in ion-exchange and chromatographic columns. J. Phys. Chem. 56, 984-988.

25 Martinez, D.E. and Bocanegra, E.M., 2002. Hydrogeochemistry and cation-exchange processes in the coastal aquifer of Mar Del Plata, Argentina. Hydrogeology Journal, 10:393-408. 
Parkhurst, D.L. and Appelo, C.A.J., 1999. User's guide to PHREEQC (v2)- A computer program for speciation, batch-reaction, one-dimensional transport and inverse geochemical calculations. U.S. Geological Survey. Water-resources Investigations Report 99-4259, 312 pp.

Petales, C. and Lambrakis, N., 2006. Simulation of intense salinization phenomena in coastal aquifers-the case of coastal aquifers of Thrace. J. Hydrol., 324: 51-64.

Plummer, L.N., Busby, J.F., Lee, R.W., 1990. Geochemical modelling in the Madison aquifer in parts of Montana, Wyoming and South Dakota. Water Resour. Res. 26, 1981-2014.

Pulido-Leboeuf, P., 2004. Seawater intrusion and associated processes in a small coastal aquifer (Castell de Ferro, Spain). Applied Geochemistry, 19: 1517-1527

Rezaei, M, Sanz, E., Raeisi, E., Ayora, C., Vázquez-Suñé, E. and Carrera, J., 2005. Reactive transport modeling of calcite dissolution in the fresh-salt water mixing zone. J. Hydrol., 311:282-298.

Ruiz, F., Gomis, V. and Blasco, P., 1990. Application of factor analysis to the hydrogeochemical study of a coastal aquifer. J. Hydrol., 119: 169-177.

Slomp, C.P. and Van Cappellen, P., 2004. Nutrient inputs to the coastal ocean through submarina 15 graoundwater discharge: controls and potential impact. Journal of Hydrology 295: 64-86.

Stuyfzand, P.J., 1992. Behaviour of major and trace constituents in fresh and salt intrusion waters, in the Western Netherlands. Proceedings of the 12th Salt-Water Intrusion Meeting, Barcelona, CIHS-CIMNE, 143-160.

Sullivan, E.J., Reimus, P.W. and Counce, D.A., 2003. Transport of a reactive tracer in saturated alluvium 20 described using a three-component cation-exchange model. J. Cont. Hydrol., 62-63: 675-694.

Toride, N., Leij, F.J. and Van Genuchten, M.T., 1995. The CXTFIT code for estimating transport parameters from laboratory or field tracer experiments, version 2. US Salinity Lab. Res. Rep. 137. Riverside, Cal.

Valocchi, A.J., Street, R.L. and Roberts, P.V., 1981a. Transport of ion-exchanging solutes in groundwater: 25 chromatographic theory and field simulation. Water Resour. Res. 17: 1517-1527

Valocchi, A.J., Roberts, P.V., Parks, G.A. and Street, R.L., 1981b. Simulation of the transport of ionexchanging solutes using laboratory-determined chemical parameter values. Ground Water 19: 600-607. 
Van Breukelen, B.M., Appelo, C.A.J. and Olsthoorn, T.N., 1998. Hydrogeochemical transport modelling of 24 years of Rhine water infiltration in the dunes of the Amsterdam water supply. J. Hydrol. 209: 281-296.

Vulava, V.M., Kretzschmar, R., Barmettler, K. and Voegelin, A. 2002. Cation competition in a natural subsurface material: Prediction of transport behaviour. Water Resour. Res., vol. 38, 5: 262-269. 


\section{FIGURE CAPTIONS}

Figure 1. Experimental configuration of the column experiments

5 Figure 2.

a) Experimental chloride breakthrough curve (symbol) obtained in Experiment $\mathrm{I}(\mathrm{Q}=20 \mathrm{mg} / \mathrm{min}$ ), Experiment II $(\mathrm{Q}=35 \mathrm{mg} / \mathrm{min})$, Experiment $\mathrm{A}(\mathrm{Q}=82 \mathrm{mg} / \mathrm{min})$ and Experiment $\mathrm{B}(\mathrm{Q}=20 \mathrm{mg} / \mathrm{min}$, treated sediment) versus experimental time (h). Best fit of the experimental data (line, $\mathrm{T}=$ theoretical) obtained with the analytical solution of the convection-dispersion equation of ACUAINTRUSION 10 (Boluda Botella, 2006).

b) Experimental chloride breakthrough curves for the experiments versus experimental dimensionless time (time/tm).

Figure 3. Concentration of $\mathrm{Cl}, \mathrm{S}$, TIC, $\mathrm{Na}, \mathrm{K}, \mathrm{Ca}, \mathrm{Mg}$ in the effluent (mmol/L) versus dimensionless

time: (a) Experiment $\mathrm{A}(\mathrm{Q}=82 \mathrm{mg} / \mathrm{min})$

(b) Experiment $\mathrm{B}(\mathrm{Q}=20 \mathrm{mg} / \mathrm{min}$, treated sediment $)$

(c) Experiment I ( $\mathrm{Q}=20 \mathrm{mg} / \mathrm{min})$ and Experiment II (Q=35 mg/min).

Figure 4. Concentration of major cations in the effluent versus time (h) or versus dimensionless time:

a) and b) $\mathrm{Ca}, \mathrm{c}$ ) and d) $\mathrm{Mg}$, e) and f) $\mathrm{Na}$, and g) and h) $\mathrm{K}$.

Figure 5. Concentration of S and TIC in the effluent versus time (h) or versus dimensionless time:
a) and b) $\mathrm{S}$
c) and d) TIC.

25

Figure 6. Piper diagrams showing the samples obtained in column Experiments A and B. The dashed lines represent the theoretical freshwater-seawater mixing line and the continuous directed lines the pathway between fresh and sea waters.

30 Figure 7. Saturation indices of gypsum, calcite and dolomite calculated with PHREEQC (Parkhurst and Appelo, 1999) for samples obtained during column experiments under different conditions. 
Figure 1

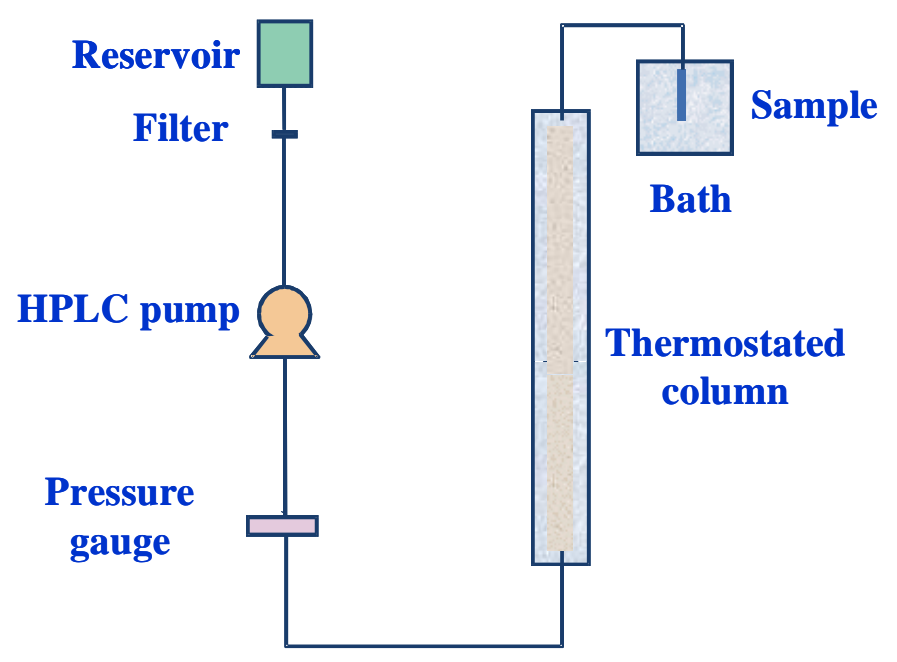


Figure 2
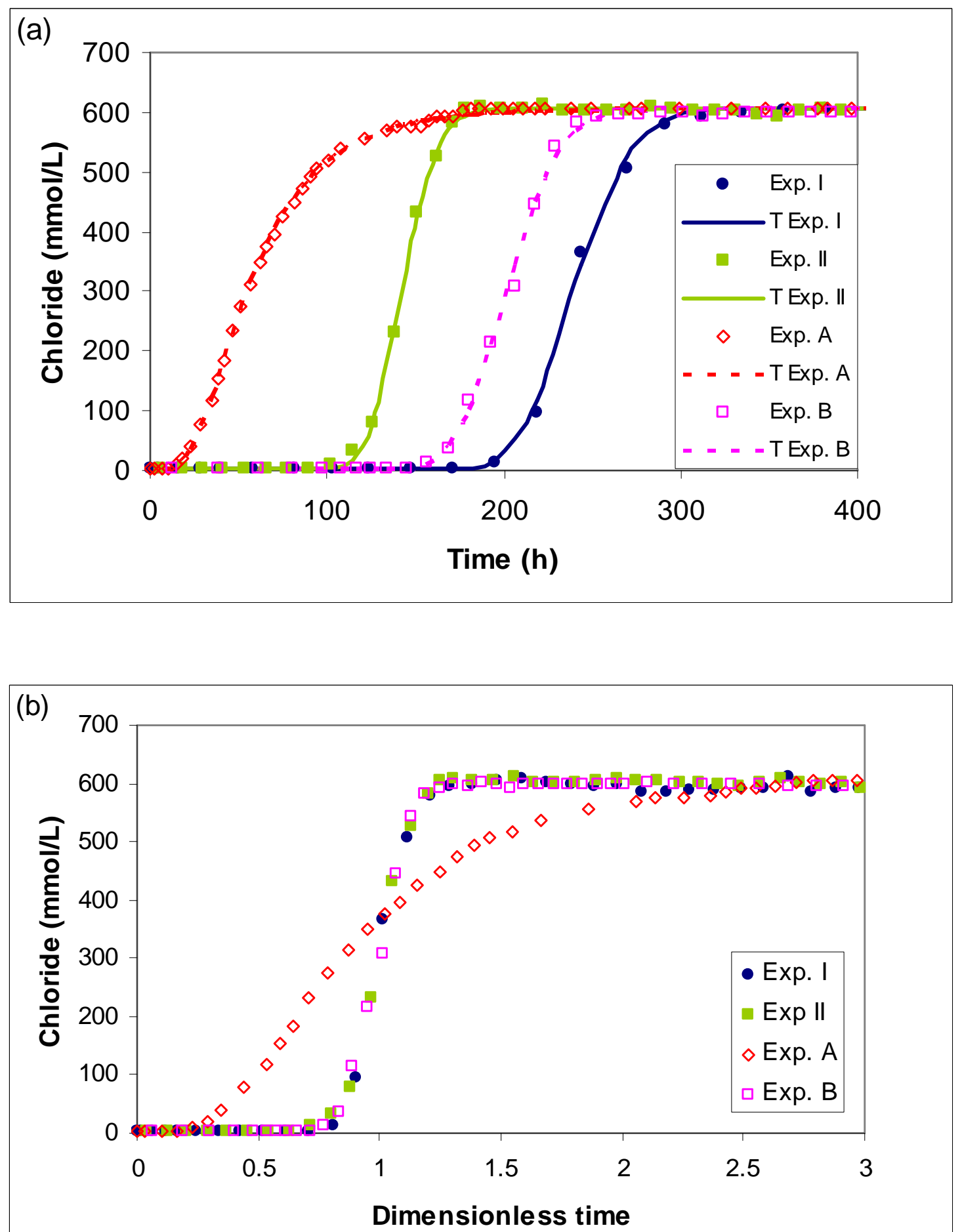
Figure 3
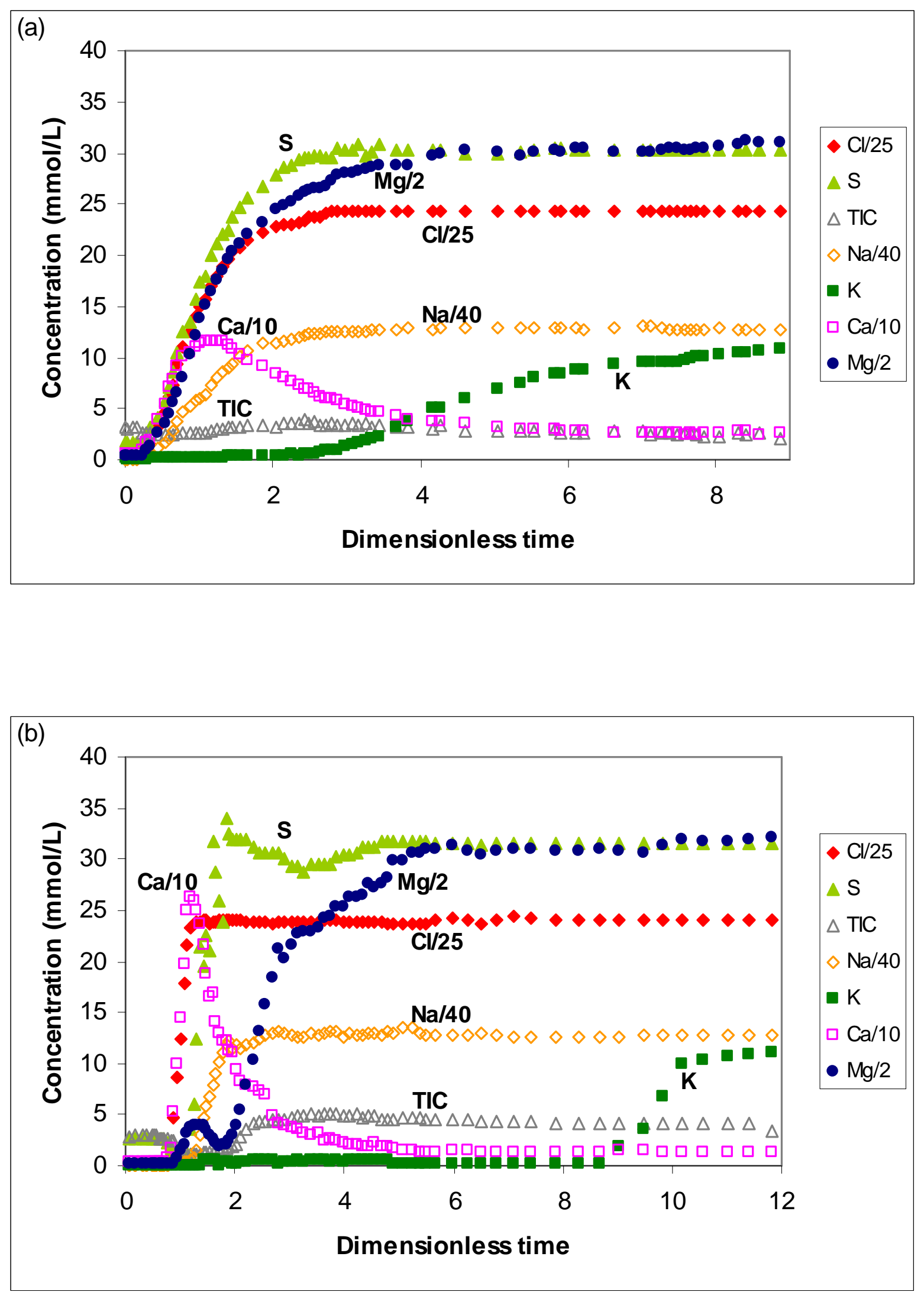


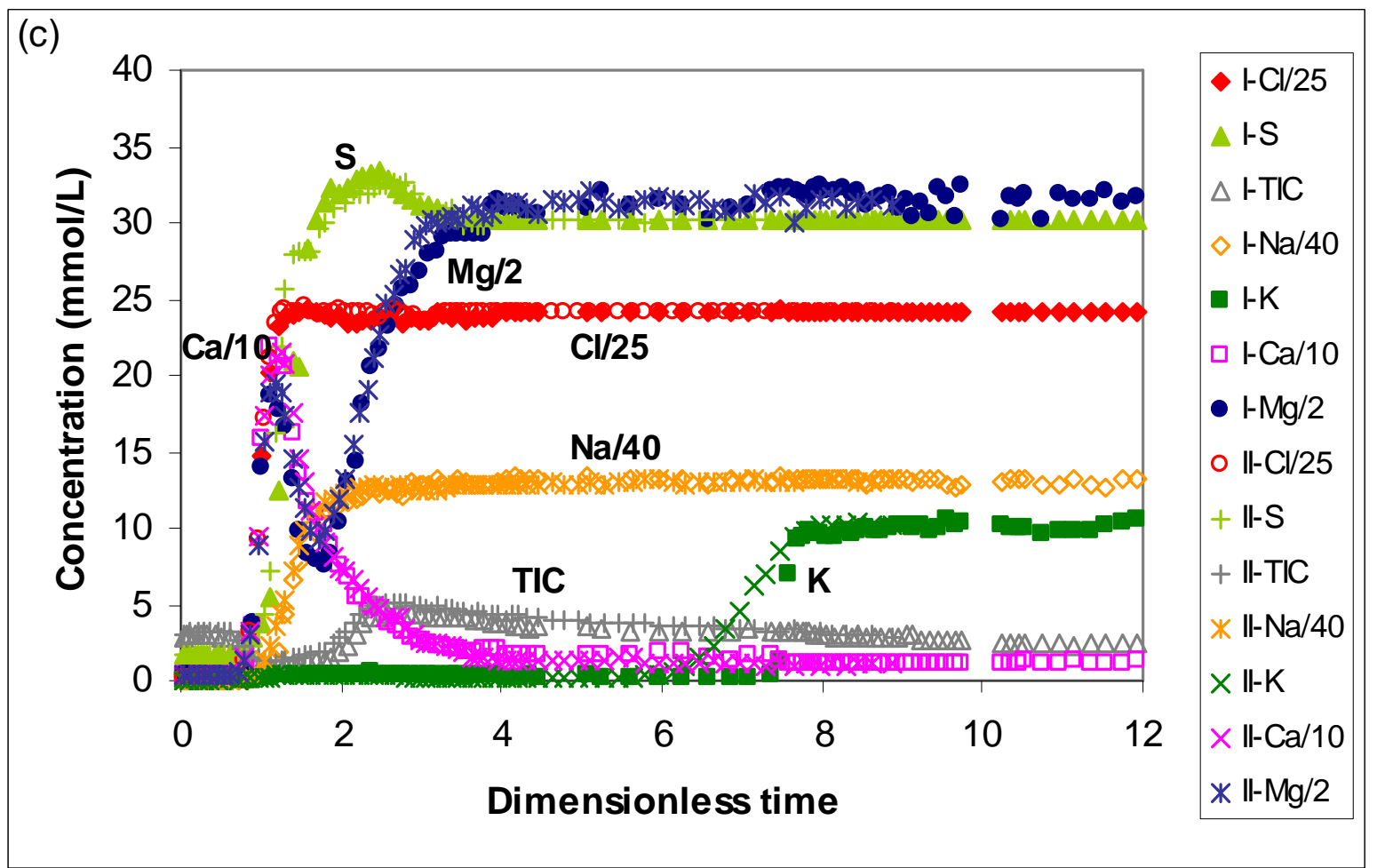


Figure 4

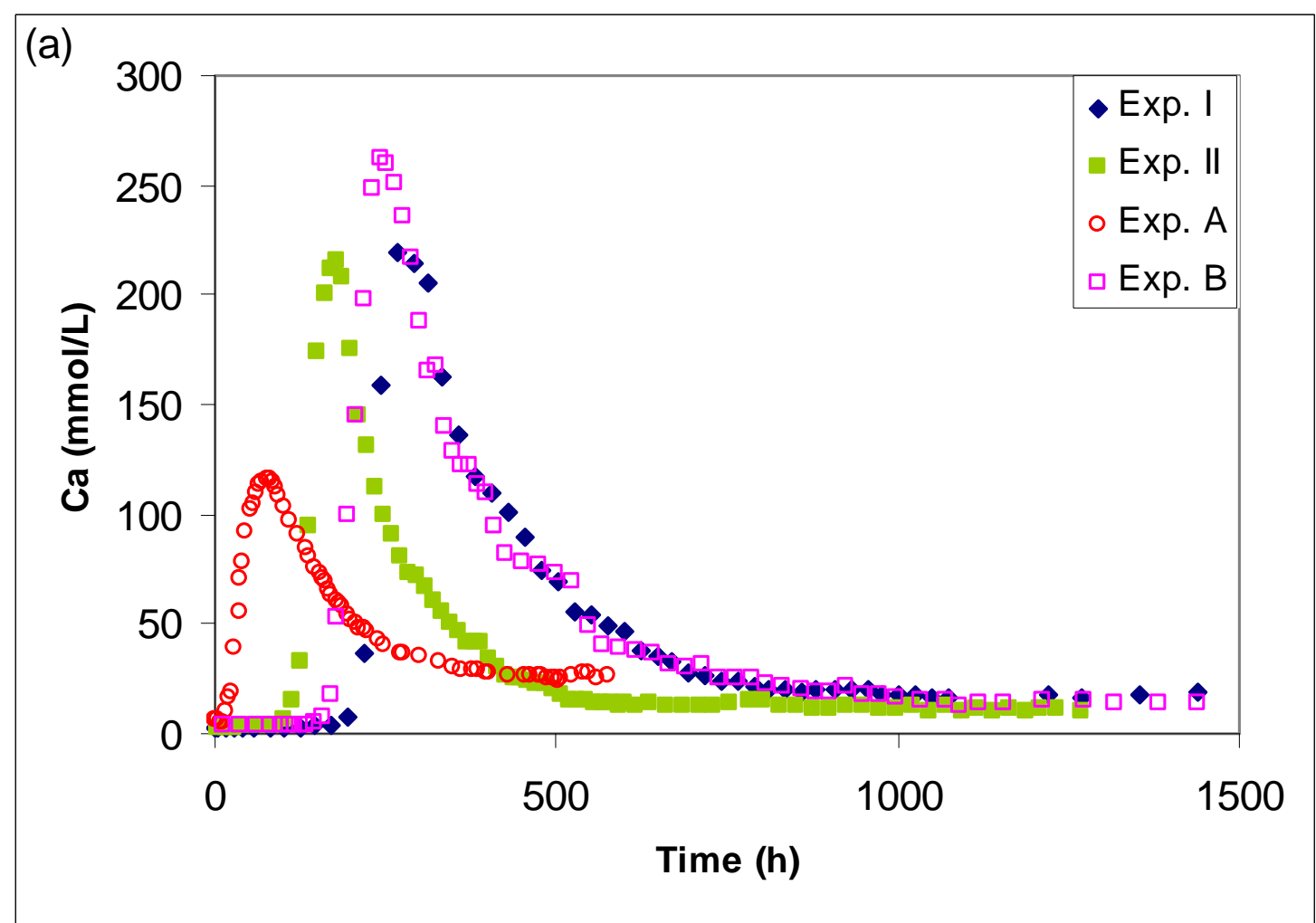

5

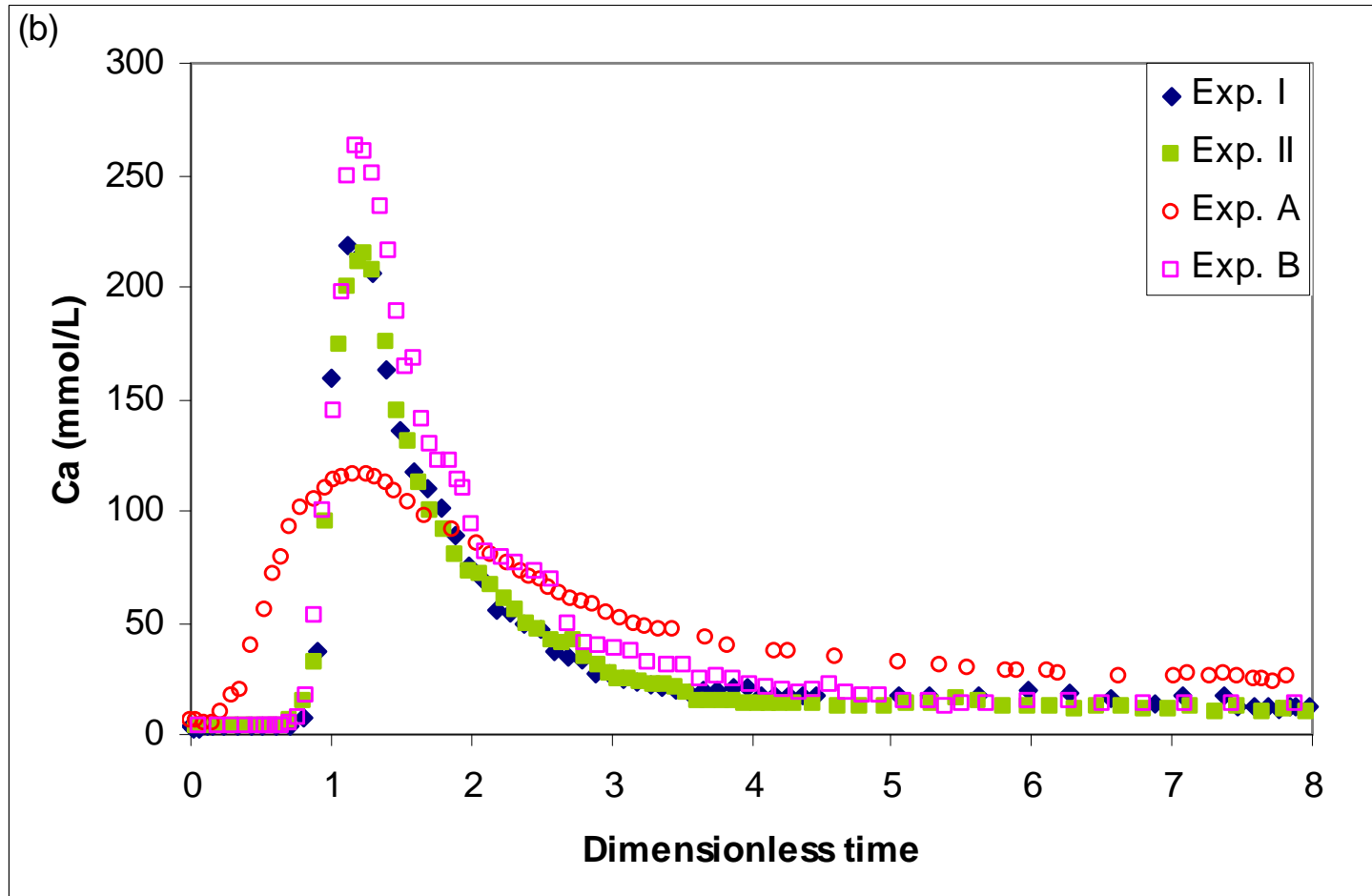




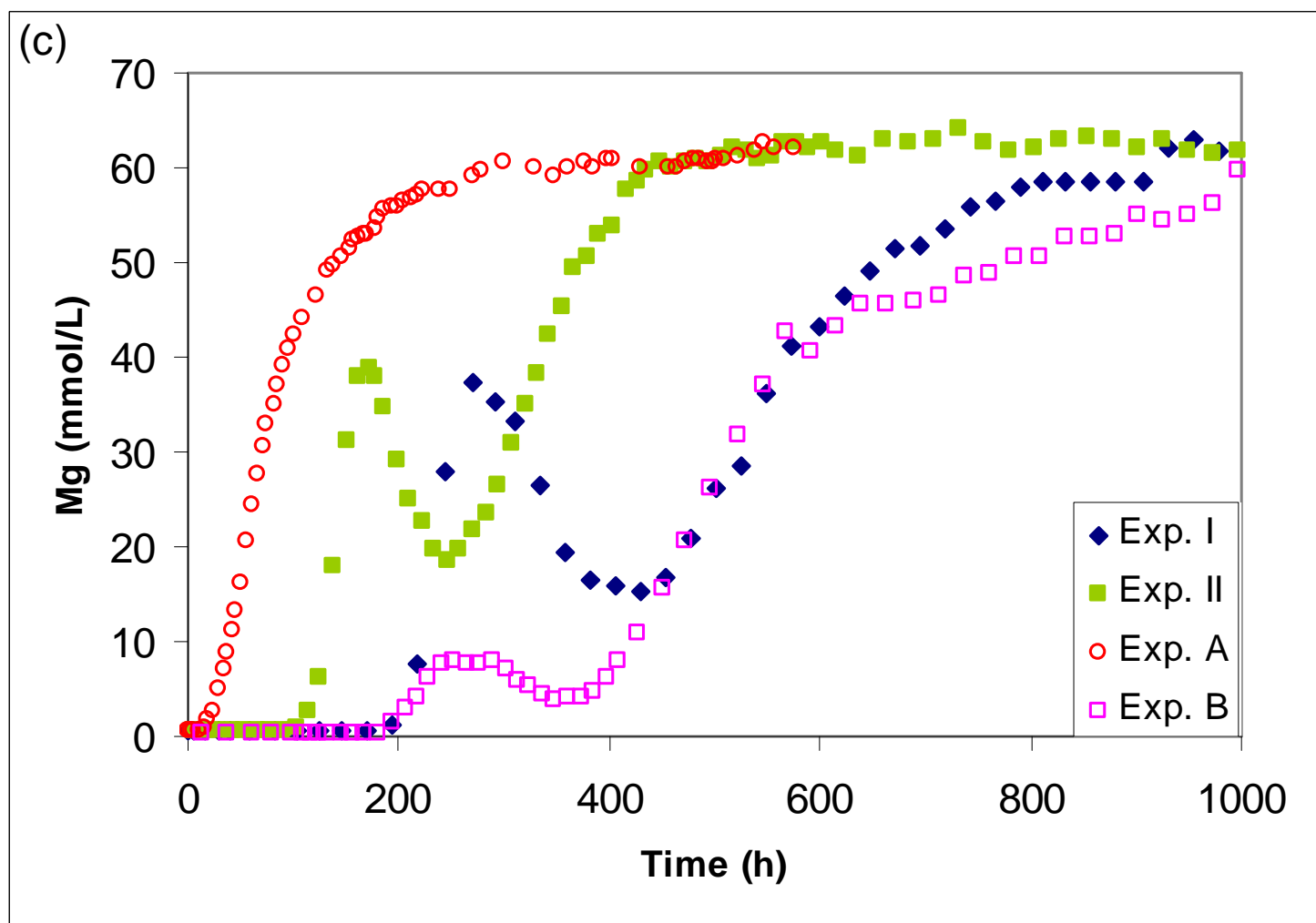

5

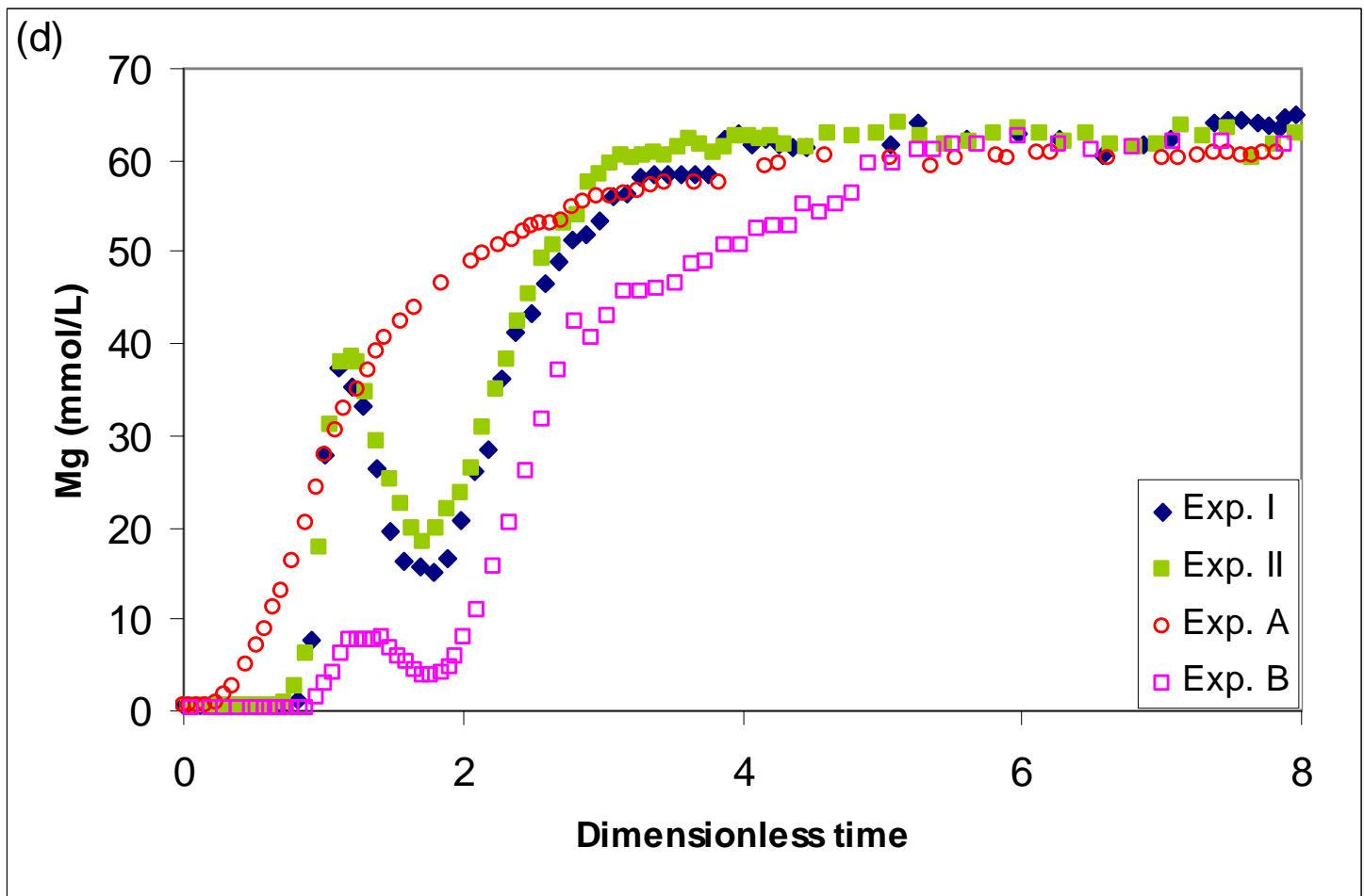



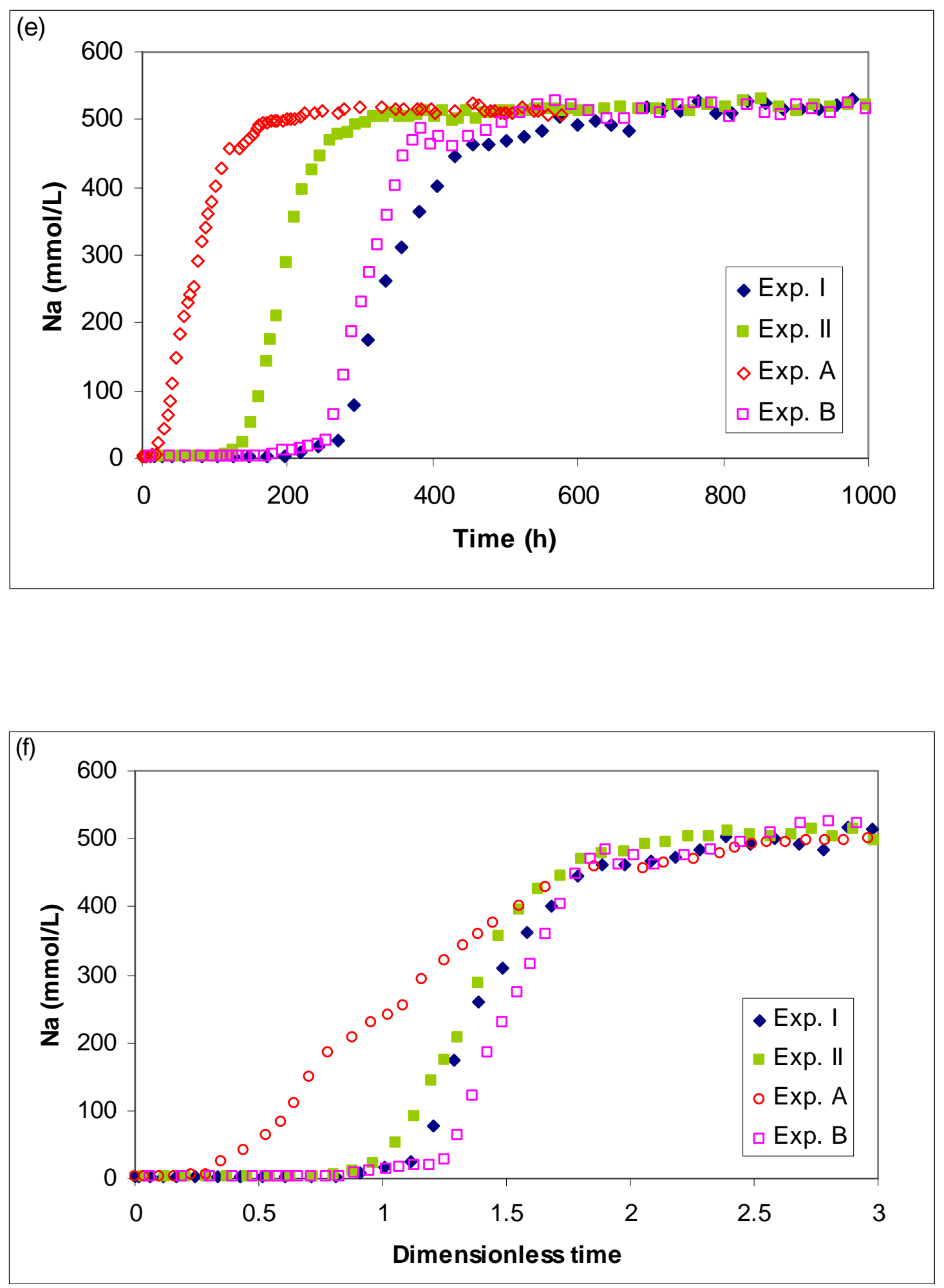


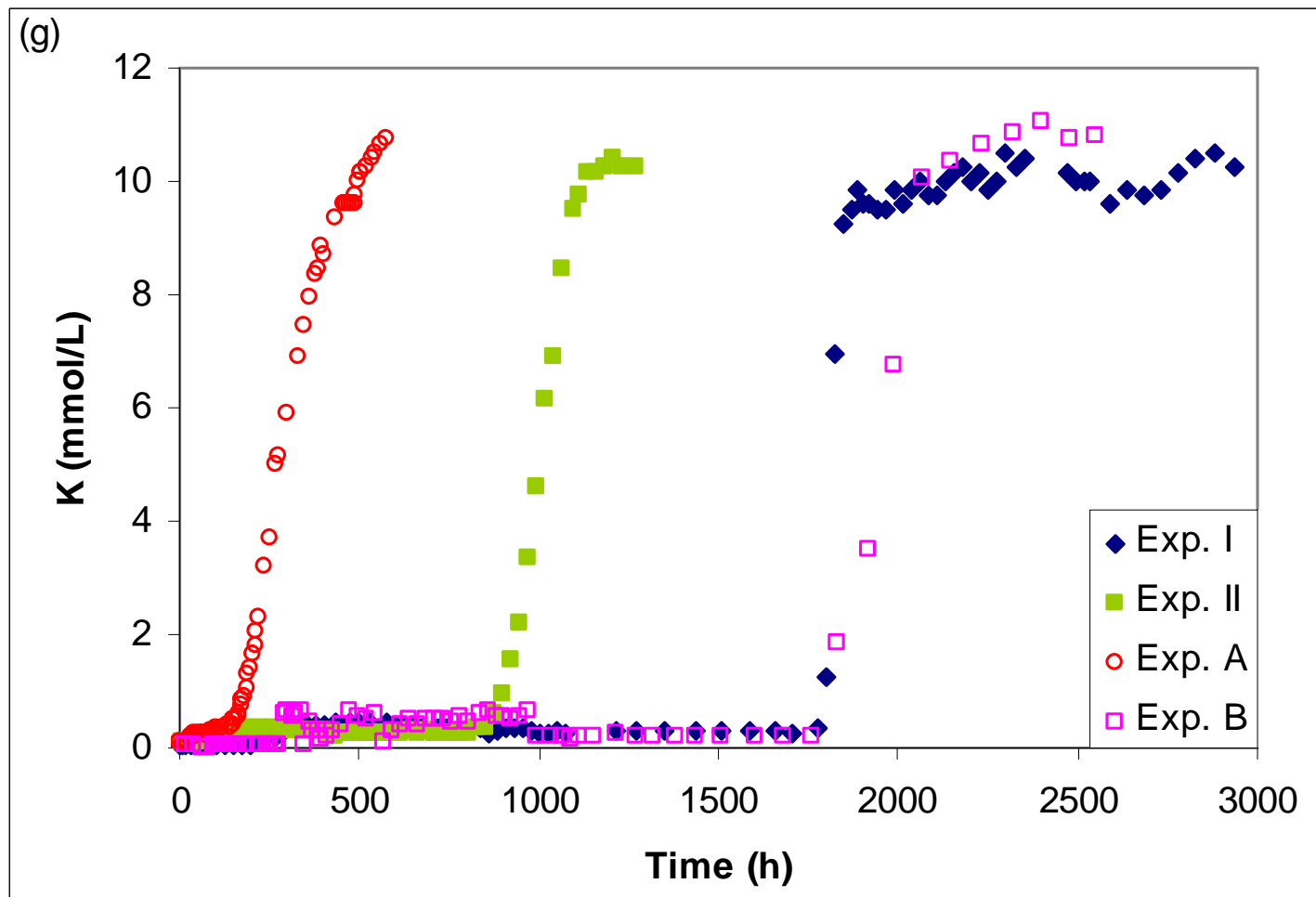

5

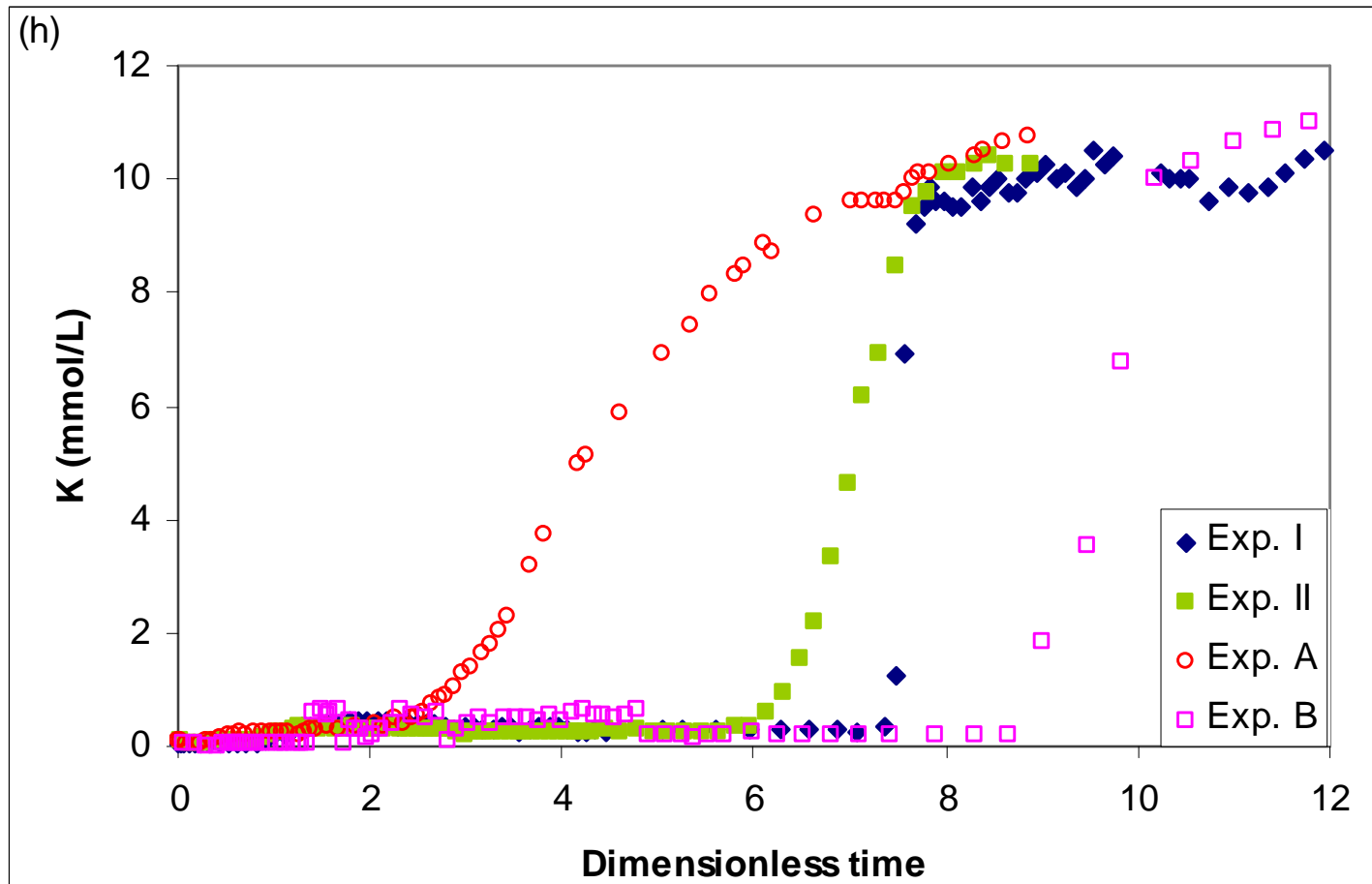


Figure 5
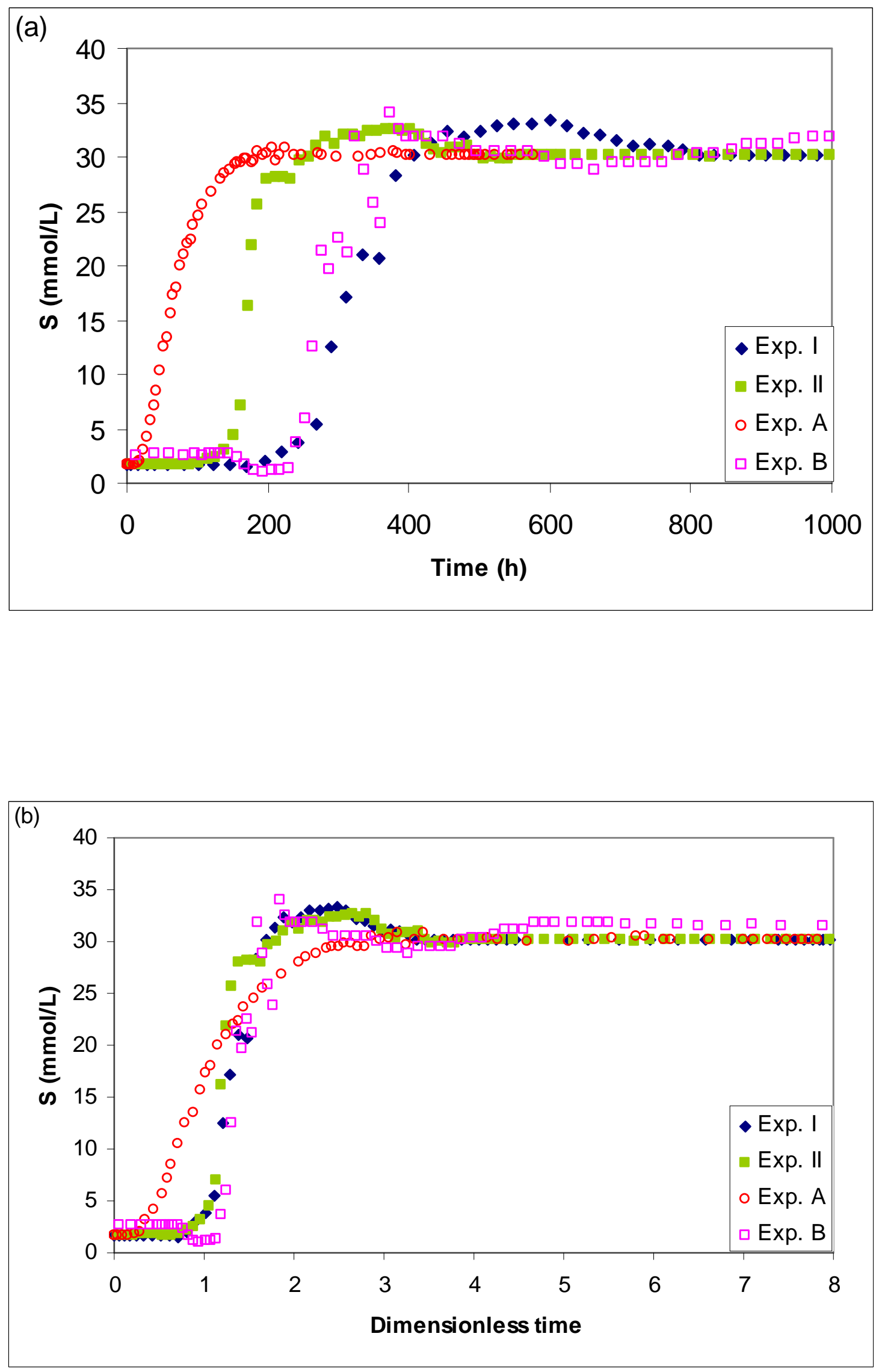

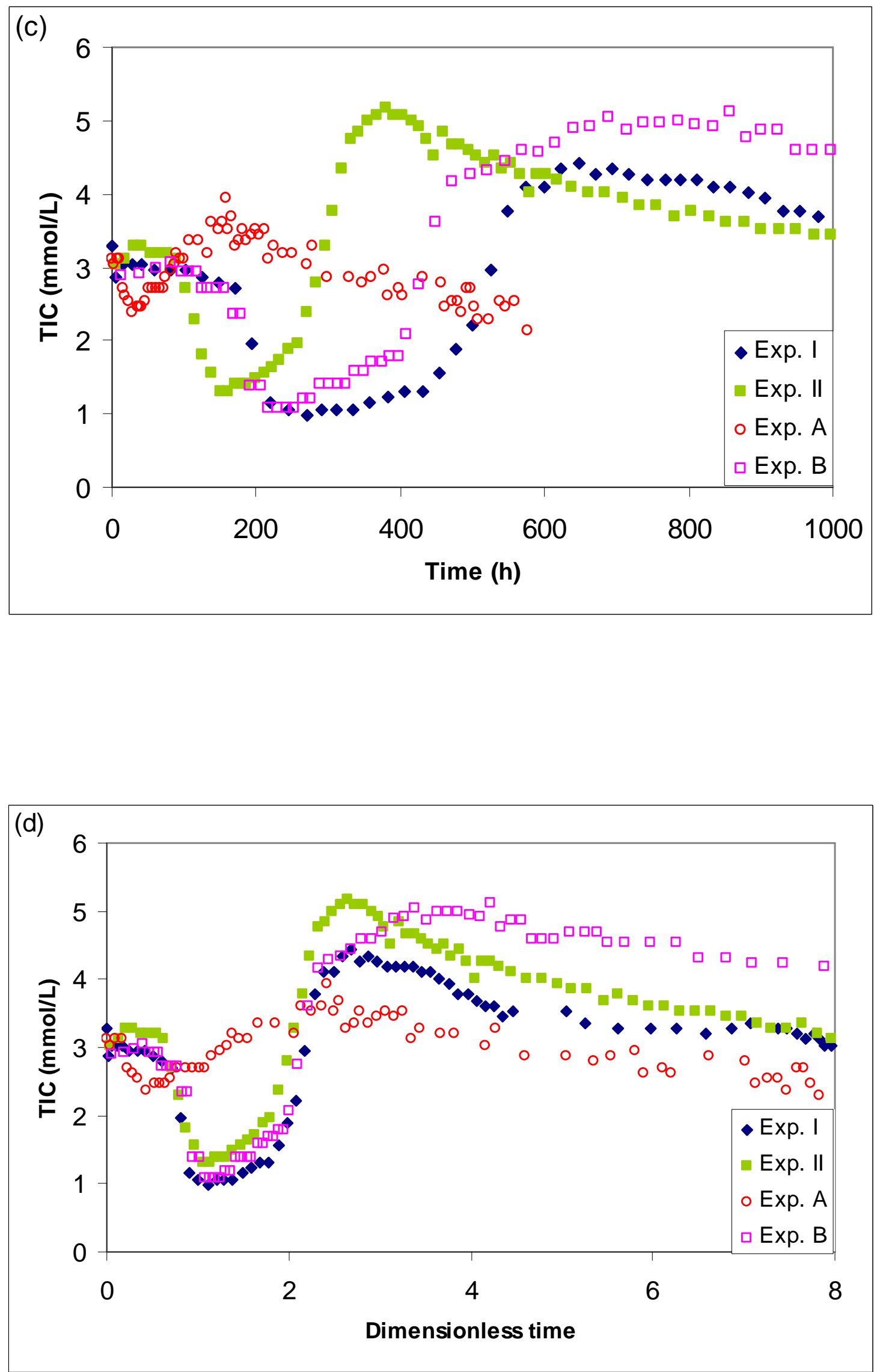
Figure 6

Piper Diagram Experiment A

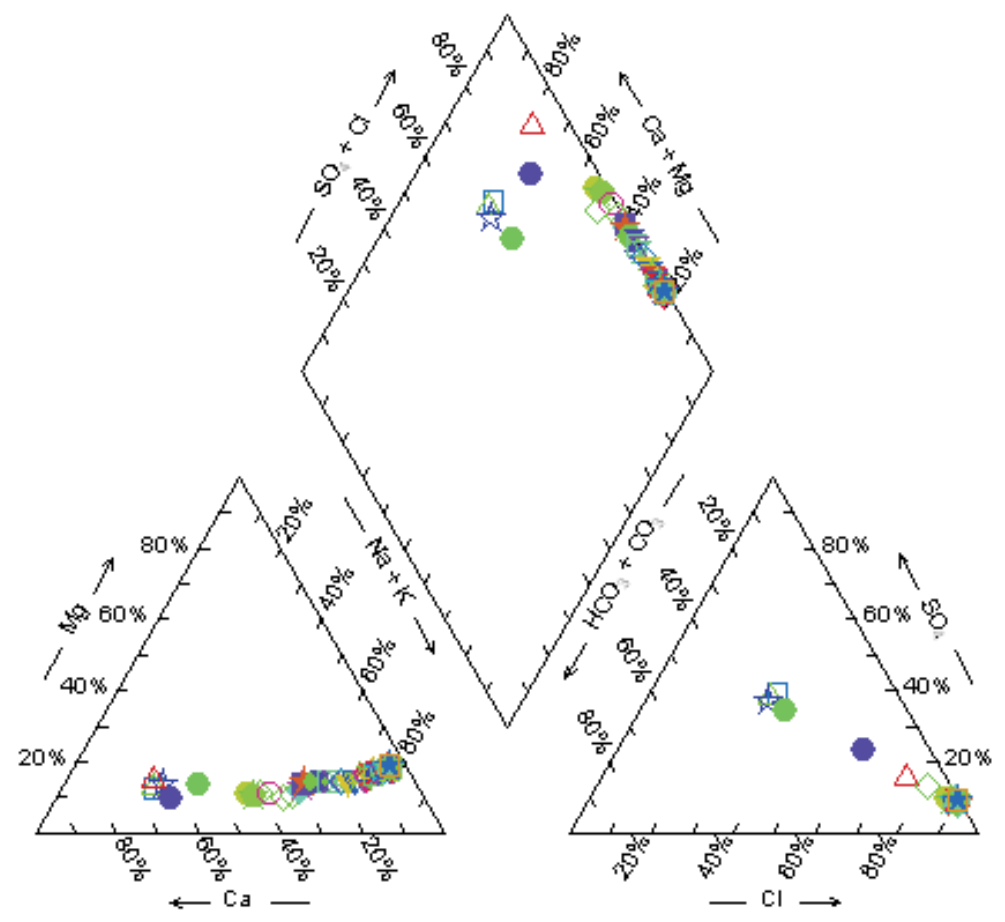

Piper Diagram Experiment B

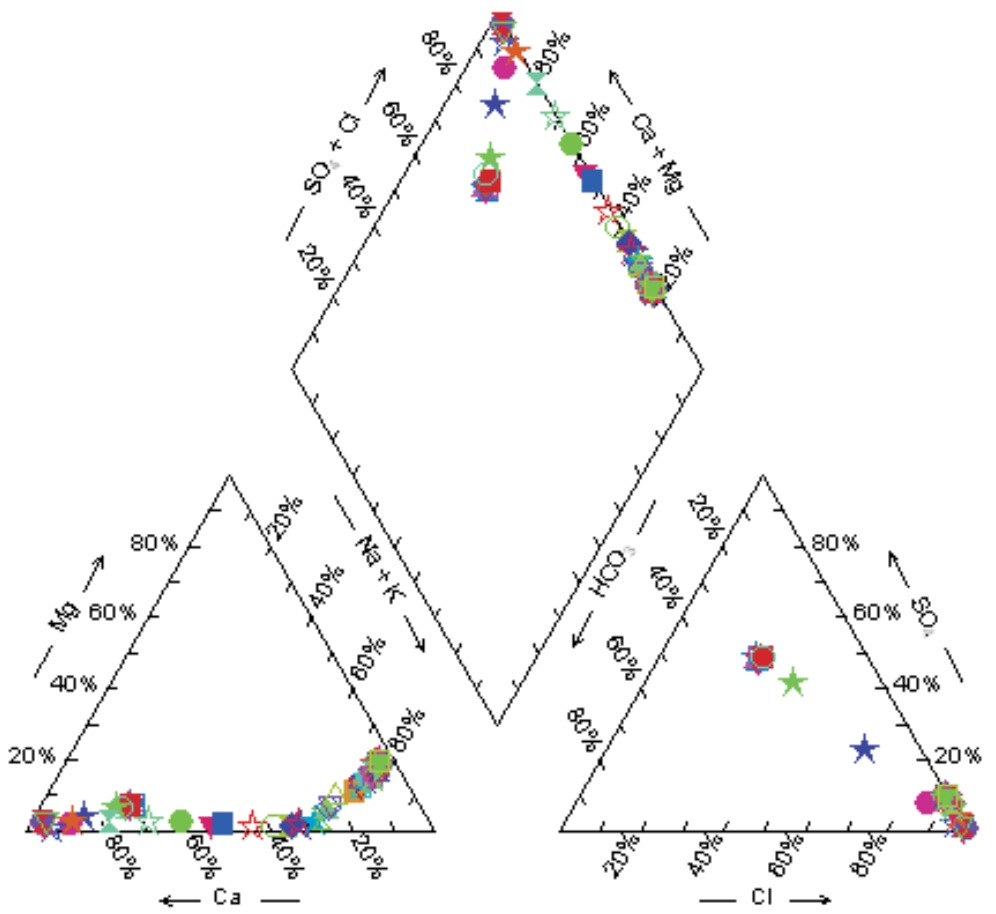


Figure 7
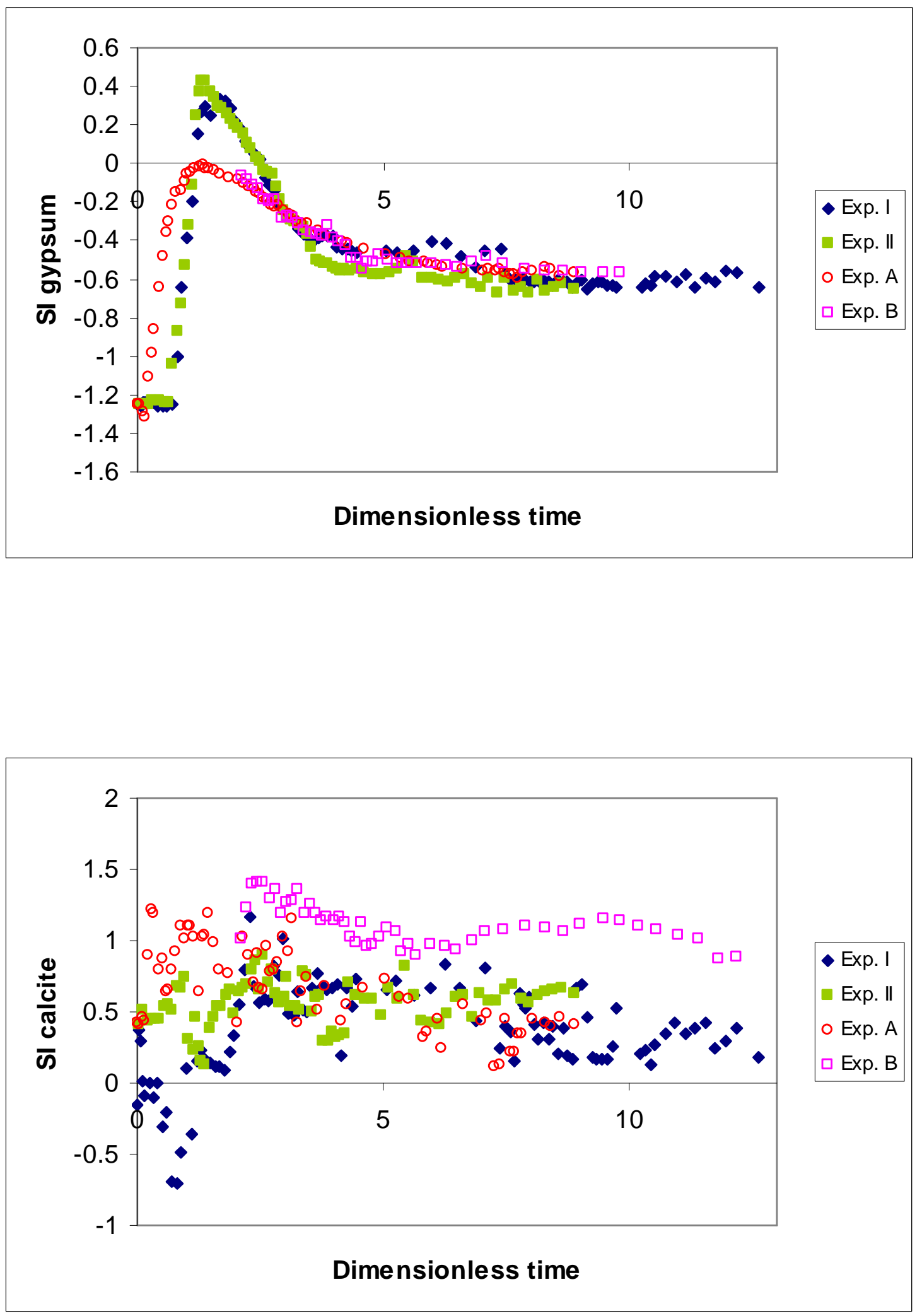


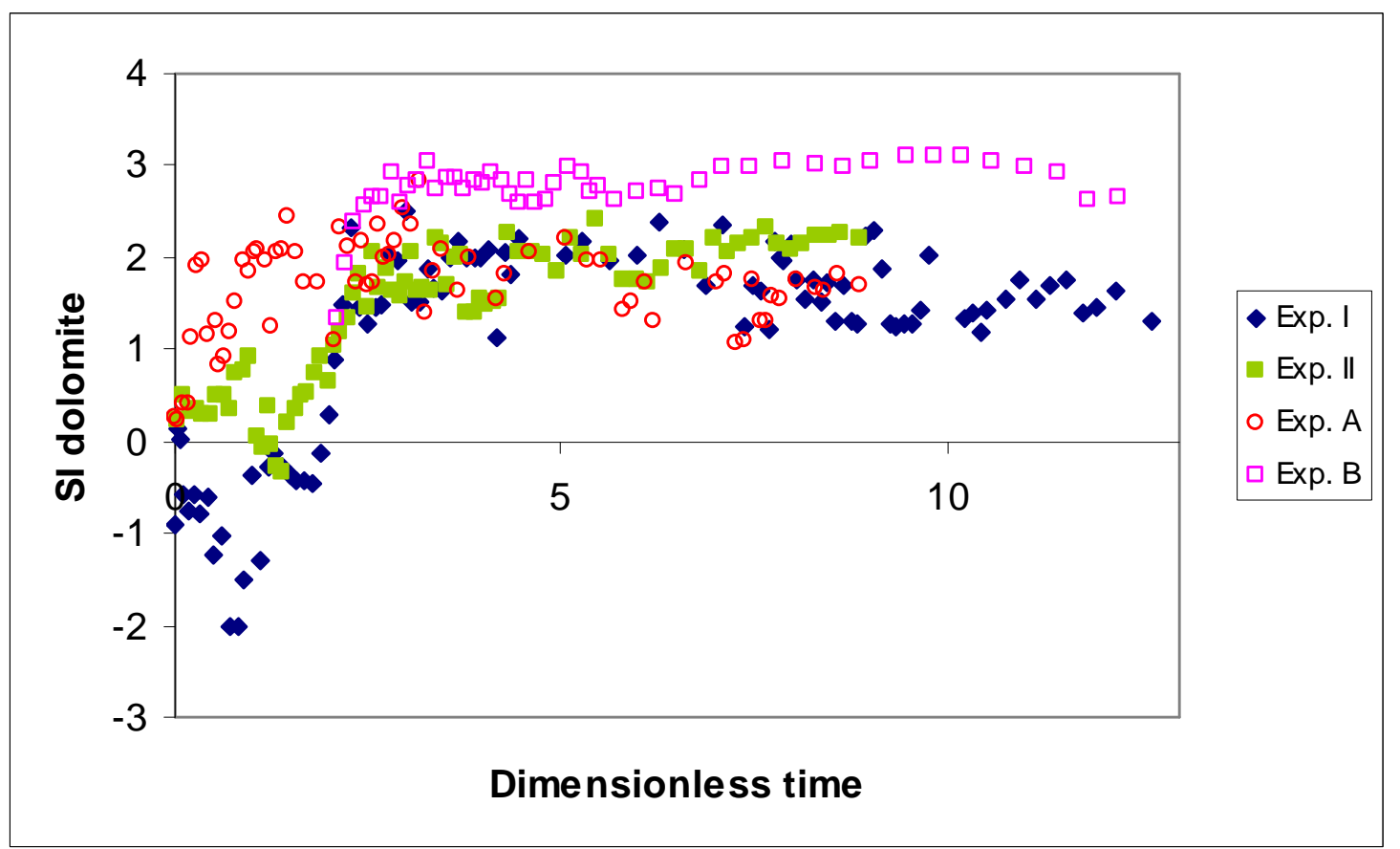

5 
Table 1. Composition of fresh and seawater used.

\begin{tabular}{|c|c|c|c|c|}
\hline \multirow{2}{*}{ Solute } & \multicolumn{2}{|c|}{ Fresh water } & \multicolumn{2}{c|}{ Seawater } \\
\cline { 2 - 5 } & $\mathbf{m g} / \mathbf{L}$ & $\mathbf{m m o l} / \mathbf{L}$ & $\mathbf{m g} / \mathbf{L}$ & $\mathbf{m m o l} / \mathbf{L}$ \\
\hline $\mathbf{N a}$ & 50 & 2.17 & 12000 & 522 \\
\hline $\mathbf{K}$ & 3.4 & 0.0872 & 400 & 10.3 \\
\hline $\mathbf{C a}$ & 125 & 3.13 & 450 & 11.3 \\
\hline $\mathbf{M g}$ & 15 & 0.617 & 1500 & 61.7 \\
\hline $\mathbf{C l}$ & 105 & 2.96 & 21500 & 606 \\
\hline $\mathbf{S}$ & 55 & 1.72 & 970 & 30.2 \\
\hline TIC & 40 & 3.28 & 26 & 2.13 \\
\hline $\mathbf{p H}$ & & 7 & \multicolumn{2}{|c}{8.2} \\
\hline
\end{tabular}


Table 2. The average results of analysis of pore solution and the exchange complex composition for the natural sediment and treated sediment.

5

\begin{tabular}{|c|c|c|c|c|}
\hline & \multicolumn{2}{|c|}{ Natural sediment } & \multicolumn{2}{c|}{ Treated sediment } \\
\hline & $\begin{array}{c}\text { Pore solution } \\
(\mathrm{mmol} / \mathrm{L})\end{array}$ & $\begin{array}{c}\text { Exchange complex } \\
(\mathrm{meq} / 100 \mathrm{~g})\end{array}$ & $\begin{array}{c}\text { Pore solution } \\
(\mathrm{mmol} / \mathrm{L})\end{array}$ & $\begin{array}{c}\text { Exchange complex } \\
(\mathrm{meq} / 100 \mathrm{~g})\end{array}$ \\
\hline $\mathrm{CEC}$ & & 7 & & 10 \\
\hline $\mathrm{Na}$ & 2.29 & 0.09 & 2.20 & 0.25 \\
\hline $\mathrm{K}$ & 0.07 & 0.10 & 0.09 & 0.13 \\
\hline $\mathrm{Ca}$ & 3.03 & 5.71 & 3.05 & 8.35 \\
\hline $\mathrm{Mg}$ & 1.08 & 1.10 & 1.28 & 1.27 \\
\hline $\mathrm{Cl}$ & 3.67 & & 3.70 & \\
\hline $\mathrm{S}$ & 1.84 & & 1.97 & \\
\hline $\mathrm{TIC}$ & 3.32 & & 3.40 & \\
\hline $\mathrm{pH}$ & 7 & & & 7 \\
\hline
\end{tabular}


Table 3. The values of transport parameters obtained with ACUAINTRUSION (Boluda Botella et al., 2006) for the previous (I and II) and recent (A and B) experiments.

\begin{tabular}{|l|c|l|c|c|c|c|c|c|c|}
\hline Exp & $\begin{array}{c}\mathrm{Q} \\
(\mathrm{mg} / \mathrm{min}\end{array}$ & $\begin{array}{l}\text { Porous } \\
\text { media }\end{array}$ & $\begin{array}{c}\mathrm{u} \\
(\mathrm{cm} / \mathrm{h})\end{array}$ & $\begin{array}{c}\mathrm{Tm} \\
(\mathrm{h})\end{array}$ & $\mathrm{Pe}=\mathrm{vL} / \mathrm{D}$ & $\varepsilon$ & $\begin{array}{c}\mathrm{v} \\
(\mathrm{cm} / \mathrm{h})\end{array}$ & $\begin{array}{c}\mathrm{D}_{\mathrm{L}} \\
\left(\mathrm{cm}^{2} / \mathrm{h}\right)\end{array}$ & $\begin{array}{c}\alpha \\
(\mathrm{cm})\end{array}$ \\
\hline I & 20 & Natural & 0.15 & 241 & 183 & 0.37 & 0.41 & 0.23 & 0.55 \\
\hline II & 35 & Natural & 0.27 & 143 & 166 & 0.38 & 0.70 & 0.42 & 0.60 \\
\hline A & 82 & Natural & 0.63 & 65 & 5.6 & 0.41 & 1.54 & 27.3 & 17.7 \\
\hline B & 20 & Treated & 0.15 & 203 & 147 & 0.31 & 0.49 & 0.33 & 0.68 \\
\hline
\end{tabular}

